\title{
Properties of the Endosomal-Lysosomal System in the Human Central Nervous System: Disturbances Mark Most Neurons in Populations at Risk to Degenerate in Alzheimer's Disease
}

\author{
Anne M. Cataldo, ${ }^{1,2}$ Deborah J. Hamilton, ${ }^{1}$ Jody L. Barnett, ${ }^{1}$ Peter A. Paskevich, ${ }^{1}$ and Ralph A. Nixon ${ }^{1,2,3}$ \\ 1 Laboratories for Molecular Neuroscience, McLean Hospital, and '2Departments of Psychiatry and Neuropathology and \\ 3Program in Neuroscience, Harvard Medical School, Belmont, Massachusetts 02178
}

Specific antibodies and cytochemical markers combined with several imaging and morphometric techniques were used to characterize the endosomal-lysosomal system in mature neurons of the normal human central nervous system and to quantitate changes in its function in Alzheimer's disease. Compartments containing cathepsin $D(C a t D$ ) and other acid hydrolases included a major subpopulation of mature lysosomes lacking mannose-6-phosphate receptors (MPR) and smaller populations of late endosomes (MPR-positive) and lipofuscin granules (MPR-negative). Antibodies to the pro-isoform of Cat $\mathrm{D}$ decorated perinuclear vacuolar compartments corresponding to late endosomes. Neurons and glia contained lysosomes with differing complements of acid hydrolases, implying different processing capabilities. Endosome/lysosome number per unit volume of cytoplasm was relatively well conserved within populations of normal neurons. By contrast, in morphometric analyses of Alzheimer's disease brains, $80-93 \%$ of pyramidal cells in the prefrontal cortex (laminae III or V) and hippocampus (CA2, CA3) displayed two- to eightfold higher numbers of hydrolase-positive vacuolar compartments than did corre- sponding cell populations in age-matched normal brains. Only $5-10 \%$ of cerebellar Purkinje cells, a less vulnerable population, showed the same statistically significant elevations. Most affected neurons in these brain regions and in subcortical areas seemed otherwise normal by conventional histological staining and ultrastructural inspection. That both lysosomal and pro-Cat $D$ - and MPR-positive endosomal compartments increased in number demonstrates that the endosomal-lysosomal system is activated markedly in vulnerable neuronal populations of Alzheimer's disease brains and implies that endocytosis or autophagy or both are accelerated persistently at an early stage of cellular compromise, greatly surpassing the degree of activity associated with normal aging. Early activation of the endosomal-lysosomal system represents a biological event potentially linking major etiological factors in Alzheimer's disease, including defective membrane proteins, apolipoprotein E function, and altered amyloid precursor protein processing.

Key words: lysosomal hydrolases; neurodegenerative disease; amyloid; lipofuscin; senile plaques; aging
The endosomal-lysosomal system is a highly dynamic and polymorphic system of acidified cytoplasmic organelles that serve key roles in cell function (Kornfeld and Mellman, 1989; Sahagian and Novikoff, 1994; Nixon and Cataldo, 1995). Rapid and extensive communication among these compartments by receptor-targeted membrane fusion creates an efficient mechanism for protcin and membrane trafficking and processing between the Golgi apparatus and the plasma membrane (Klausner, 1989; Sahagian and Novikoff, 1994). A battery of more than two dozen acid hydrolases, including proteases or cathepsins, are shuttled from the Golgi apparatus to late endosomes that contain intracellular material engulfed during autophagy or extracellular material derived from heterophagy (Gordon and Seglen, 1988; Dunn, 1990; Gordon et al., 1992). A family of mature lysosomal compartments thereby arises, which includes dense bodies, multivesicular bodies, and autophagic vacuoles. As a result of aging or metabolic and oxidative stress, indigestible or incompletely degraded material accu-

\footnotetext{
Received Aug. 15, 1995; revised Sept. 25, 1995; accepted Oct. 2, 1995.

This work was suppurted by Public Health Service Grants AG08278 and AG05134 to R.A.N, and MH/NS31862 (McLean Tissue Resource Center). We thank Denise McCarthy and Johanne Khan for secretarial assistance and Lisa Kanaley-Andrews for technical expertisc.

Correspondence should be addressed to Dr. Anne M. Cataldo, Mailman Research Center, Laboratories for Molecular Neuroscience, 115 Mill Street, Belmont, MA 02178.

Copyright $\odot 1995$ Society for Neuroscience $0270-6474 / 95 / 160186-14 \$ 05.00 / 0$
}

mulates within these organelles, creating a heterogeneous group of residual bodies or postlysosomal compartments such as lipofuscin and ceroid (Brizzee et al., 1975; Siakotos and Armstrong, 1975).

As a major site for the degradation of cytosolic and membrane proteins and cell organelles, lysosomes replenish pools of amino acids and glucose for new protein synthesis (Seglen and Bohley, 1992). Controlled shifts in lysosomal activity allow neurons to regulate their cytoplasmic volume (Bhattacharya and von Mayersbach, 1976; Seglen and Bohley, 1992) and remodel local cellular domains during differentiation (Pannese et al., 1976; Roberts and Gorenstein, 1987). "Lysosomal" hydrolases in endosomal compartments may also carry out limited proteolysis on certain proteins to generate molecules with new functions (Diment et al., 1989; Casciola-Rosen and Hubbard, 1991; Renfrew and Hubbard, 1991). Nutritive, trophic, and regulatory molecules such as vitamin B12, cholesterol, and insulin are internalized by receptormediated endocytosis, transported to late endosomes, and processed to release functionally active molecules (Doherty et al., 1990; Idriss and Jonas, 1991). Endocytic activity is particularly high at nerve terminals and dendritic domains, and the retrograde translocation of membranous vesicles containing extracellular materials to endosome/lysosome-related compartments may be part of a mechanism for conveying molecular information, including trophic signals from the periphery (LaVail and LaVail, 1974; Baas 
and Heidemann, 1986; Parton and Dotti, 1993), as well as for recycling synaptic membrane. The importance of the endosomallysosomal system for proper brain function is underscored by the fact that extensive neuropathology, mental retardation, and often progressive cognitive decline are among the most prominent phenotypic features of the more than 30 known inherited disorders involving defects in the synthesis, sorting, or targeting of lysosomal enzymes. Despite its neurobiological importance, relatively little is known about the properties of the endosomal-lysosomal system in the nervous system, particularly in mature neurons.

An association of lysosome activation with regressive events during development and involution in some invertebrate systems previously gave rise to a notion that lysosomes are commonly and prominently involved in neurodegeneration. In many forms of neuronal cell death, however, lysosome system participation seems minimal or may even represent attempts to repair or compensate for the injury (for review, see Nixon and Cataldo, 1993). Current findings suggest that lysosomal system alterations are not part of a final common pathway to cell death in the nervous system, but instead may be a distinctive cellular response to certain types of metabolic compromise (for review, see Nixon and Cataldo, 1993). In Alzheimer's disease, however, endosomallysosomal system disturbances are prominent and have potential relevance to pathogenesis (Nixon et al., 1992; Cataldo et al., 1994, 1995). Studies using antibodies to lysosomal hydrolases have now revealed striking intracellular and extracellular manifestations of altered lysosomal function, including elevated acid hydrolase gene expression in vulnerable neuronal populations (Cataldo et al., 1995), massive accumulation of acid hydrolase-containing compartments in atrophic and degenerating neurons or their processes (Cataldo et al., 1990; Nakamura et al., 1991), and release of these lysosomal compartments into the extracellular space where they persist and contribute to senile plaque formation (Bernstein et al., 1989; Cataldo et al., 1991, 1994; Nixon and Cataldo, 1991;
Bernstein, 1994) and appear in markedly elevated levels in ventricular CSF (Schwagerl et al., 1995).

In this study we characterized the individual components of the endosomal-lysosomal system in neurons of the human brain using a combination of light microscopic, ultrastructural, and morphometric approaches involving different functional markers. We identified distinct acid hydrolase-containing vacuolar compartments in normal neurons and obtained quantitative information on changes in these compartments in Alzheimer's disease. New evidence is reported here that disturbances of endosomal-lysosomal system function are not restricted to overtly degenerating neurons but are evident in the vast majority of neurons within populations at risk to degenerate in Alzheimer's disease brain.

\section{MATERIALS AND METHODS}

Tissue. Postmortem brain tissue from 20 individuals with the probable clinical diagnosis of Alzheimer's disease and from 17 age-matched (62-78 years old), neurologically normal controls were used in this study. Tissue was procured from the Brain Tissue Resource Center at McLean Hospital (Belmont, MA) and the Neuropathology Core Facility of the Massachusetts Alzheimer's Disease Research Center (Massachusetts General Hospital, Boston, MA). Control brains ranged from 1200 to $1350 \mathrm{gm}$ in weight and exhibited no gross anatomical pathology and only minimal histopathological changes ( $0-3$ neuritic plaques/low power field; $0-6$ neurofibrillary tangles/low power field). Tissue blocks $\left(3 \times 1 \times 0.4 \mathrm{~cm}^{3}\right)$ from the frontal pole (area 10, prefrontal cortex), hippocampus, and cerebelli of all brains were cut into 30 - to $40-\mu \mathrm{m}$-thick vibratome sections or $8-\mu \mathrm{m}$-thick paraffin sections.

The presence and magnitude of neurodegeneration and neurofibrillary histopathology were confirmed on adjacent, serial vibratome, or paraffin sections from all brain regions using Nissl and Bielschowsky stains, and the diagnosis of Alzheimer's disease was established by criteria from the Consortium to Establish a Registry for Alzheimer's Disease (Mirra et al., 1991). Thioflavin $S$ was used for histological detection of the $\beta$-amyloid protein. Brain tissue used for immunocytochemical analyses was immersion-fixed in cold, $10 \%$ phosphate-buffered $(0.15 \mathrm{M})$ formalin, $\mathrm{pH} 7.4$. The postmortem interval for all brain tissue used was $0-6 \mathrm{hr}$ with a total fixation time of 2 weeks or less.
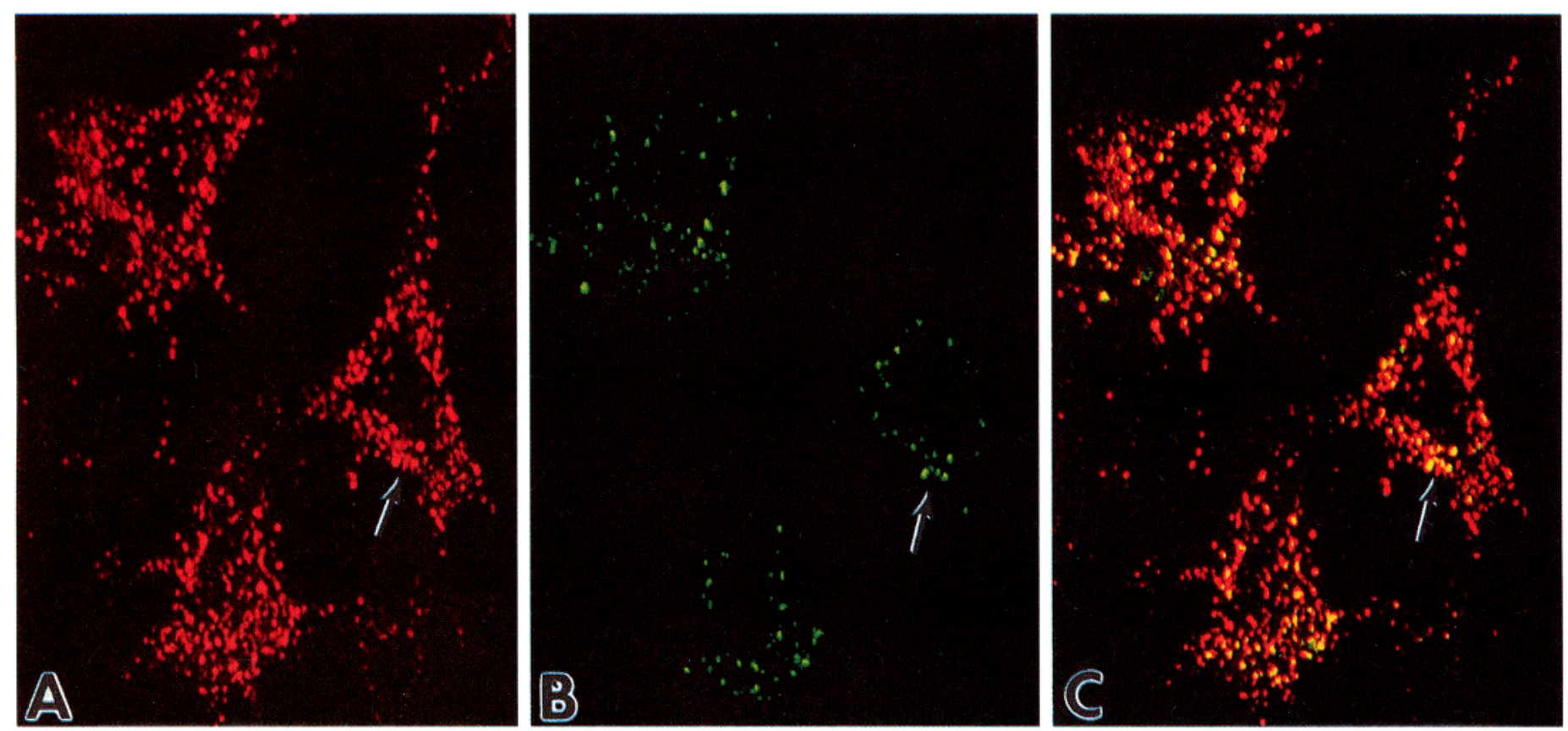

Figure 1. Hydrolase-containing endosomal-lysosomal compartments. Cat D immunoreactivity is abundant in endosomes and lysosomes of pyramidal neurons from human brain $(A$, arrow). Confocal imaging of fluoroprobes to Cat $\mathrm{D}(A$, red, arrow) and the MPR $(B$, green, arrow) in the same neurons shows hydrolase immunostaining in both MPR-positive late endosomes $(C$, yellow, arrow) and MPR-negative lysosomal compartments $(C$, red $)$. $A-C$, $4000 \times$ 

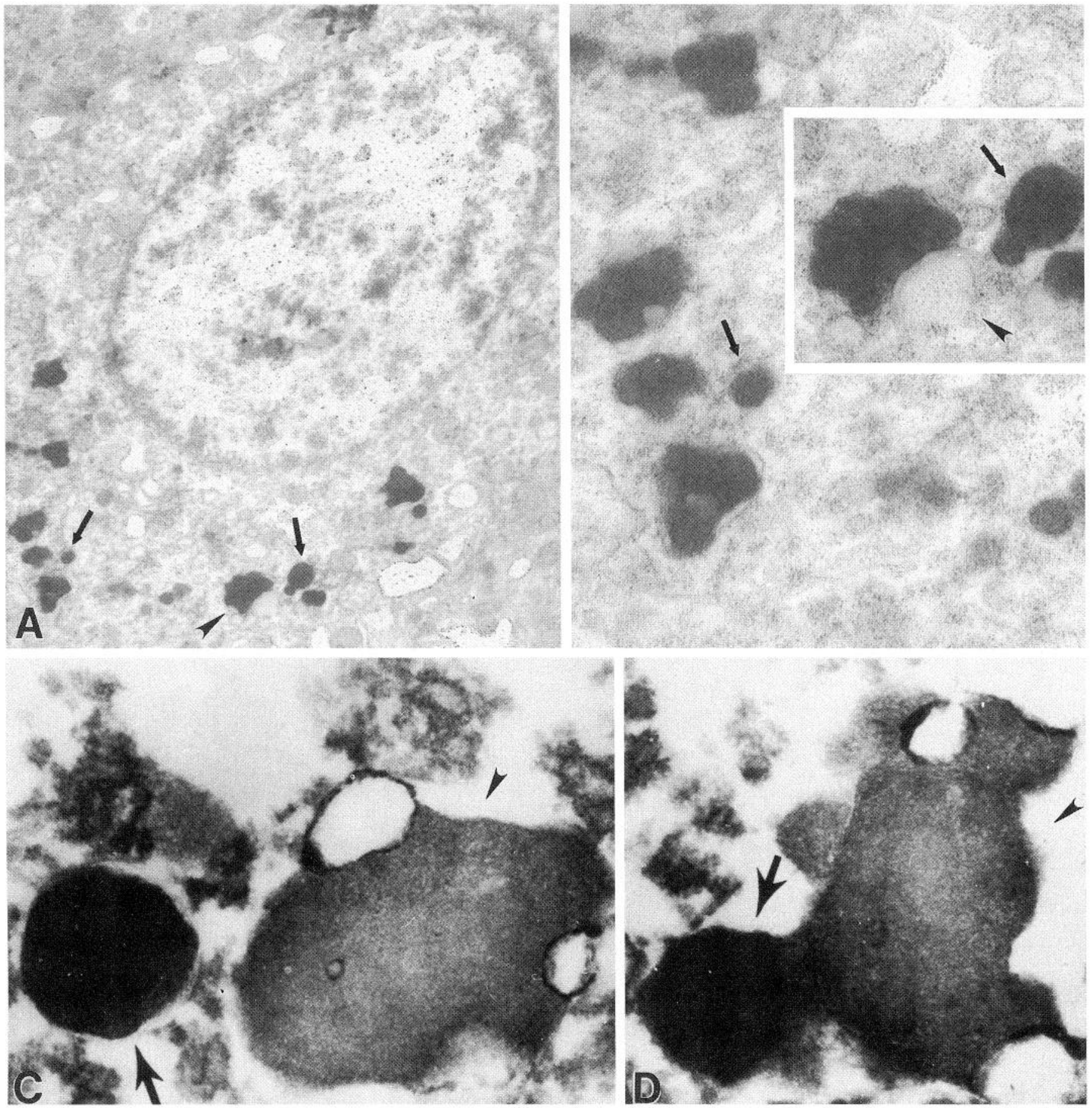

Figure 2. Immunoelectron distribution of hydrolase-positive compartments in human neurons. Cat D immunoreactivity is localized within electron-dense endosomal/lysosomal vacuolar compartments $(A-D$, arrows) and lipofuscin granules $(A-D$, arrowheads) in human cortical pyramids. The numbers of intracellular hydrolase-containing lipofuscin granules are few compared with acidic vacuolar structures. Endosomal/lysosomal compartments deliver hydrolases to postlysosomal compartments (lipofuscin granules) through the selective and regulated budding and fusion of compartmental membranes $(C, D) . A, 7500 \times ; B, B$ inset, $25,000 \times ; C, D, 55,000 \times$.

Antibodies. Immunocytochemical studies were performed using antibodies to four lysosomal hydrolases: $\beta$-hexosaminidase A (HEX), cathep$\sin$ B (Cat B), cathepsin D (Cat D) and cathepsin H (Cat H). Rabbit antiserum directed against HEX was provided by Dr. Srinivasa Raghavan (New York University Medical Center, Department of Neurology, New York, NY). Anti-Cat D antiserum was prepared in our laboratory and raised in sheep against human brain Cat D (Nixon and Marotta, 1984; Cataldo et al., 1990). Human liver anti-Cat B antiserum was purchased commercially from ICN Biochemicals (Costa Mesa, CA). Rabbit antiserum to rat liver Cat $\mathrm{H}$ was obtained from Dr. Eiki Kominami (Juntendo University, Tokyo, Japan). The anti-Pro-Cat D antiserum was purchased commercially from Oncogene Science (Cambridge, MA). Antibody directed against the mannose 6-phosphate-receptor (MPR) was provided by Dr. Stuart Kornfeld (Washington University School of Medicine, St. Louis, MO) and prepared as previously described (Hoflack and Kornfeld, 1985; Griffiths et al., 1988). 

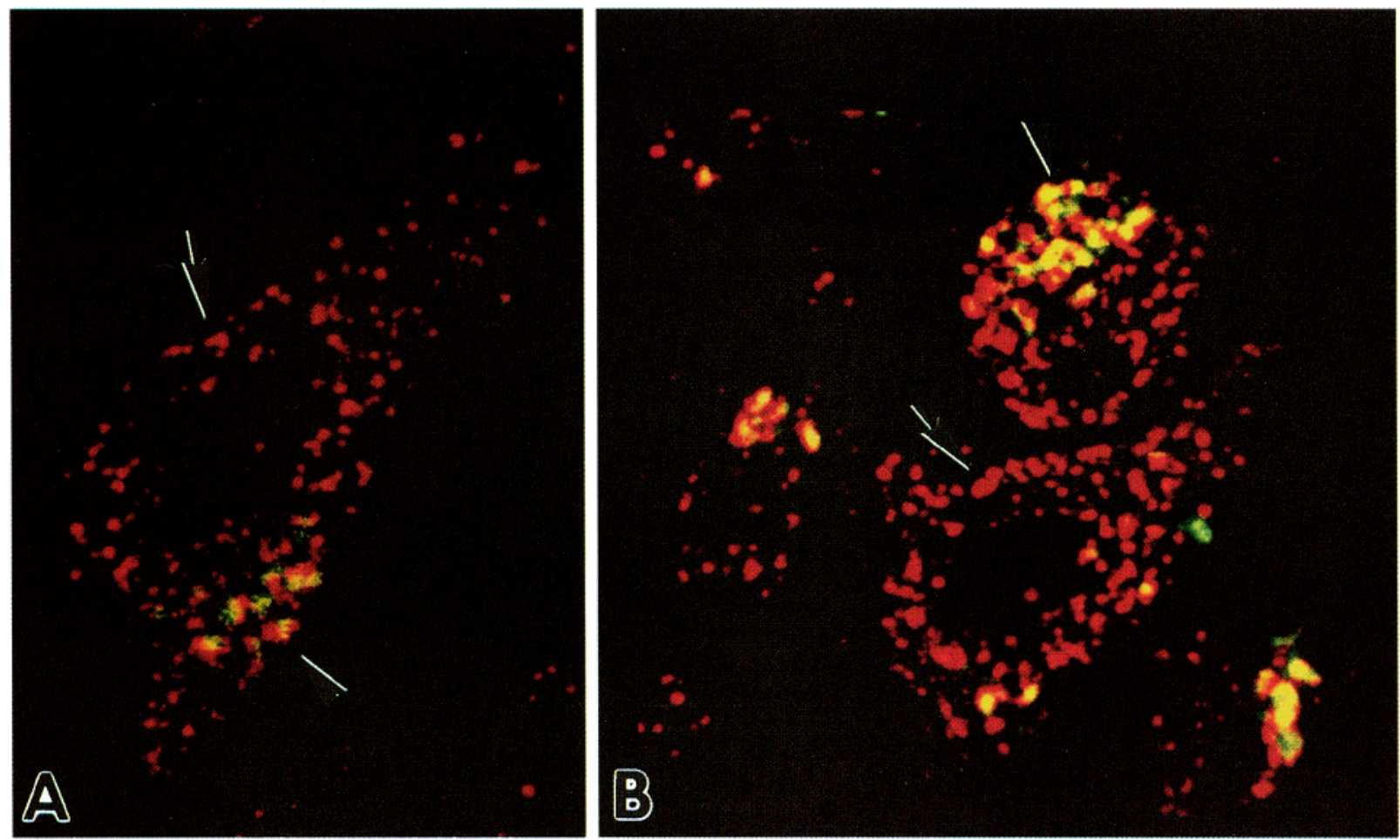

Figure 3. Postlysosomal compartments are a minor percentage of all hydrolase-containing organelles. Digital confocal image analysis using streptavidinTexas Red conjugated to Cat $\mathrm{D}(A, B, r e d)$ shows increased numbers of Cat D-positive endosomal/lysosomal compartments (arrows) present in neurons from the Alzheimer's disease $(B)$ versus control brains $(A)$. Lipofuscin granules detected in these same neurons by green autofluorescence are also Cat D-positive $(A, B$, yellow, arrowheads), but represent a small portion of the total population of mature hydrolase-positive organelles. $A, B, 5000 \times$.

Immunocytochemistry. Hydrolase immunoreactivity was demonstrated on vibratome and paraffin sections using a modification of the avidinbiotin technique of Hsu et al. (1981) and Vectastain kits (Vector Laboratories, Burlingame, CA) with diaminobenzidine as the chromagen
(Cataldo et al., 1990). Negative controls consisted of tissue sections incubated in preimmune antisera or in the absence of primary antisera. The sections were inspected with a Zeiss Axioscope. Several sections were immunostained with hydrolase antisera, and immunoreactivity was
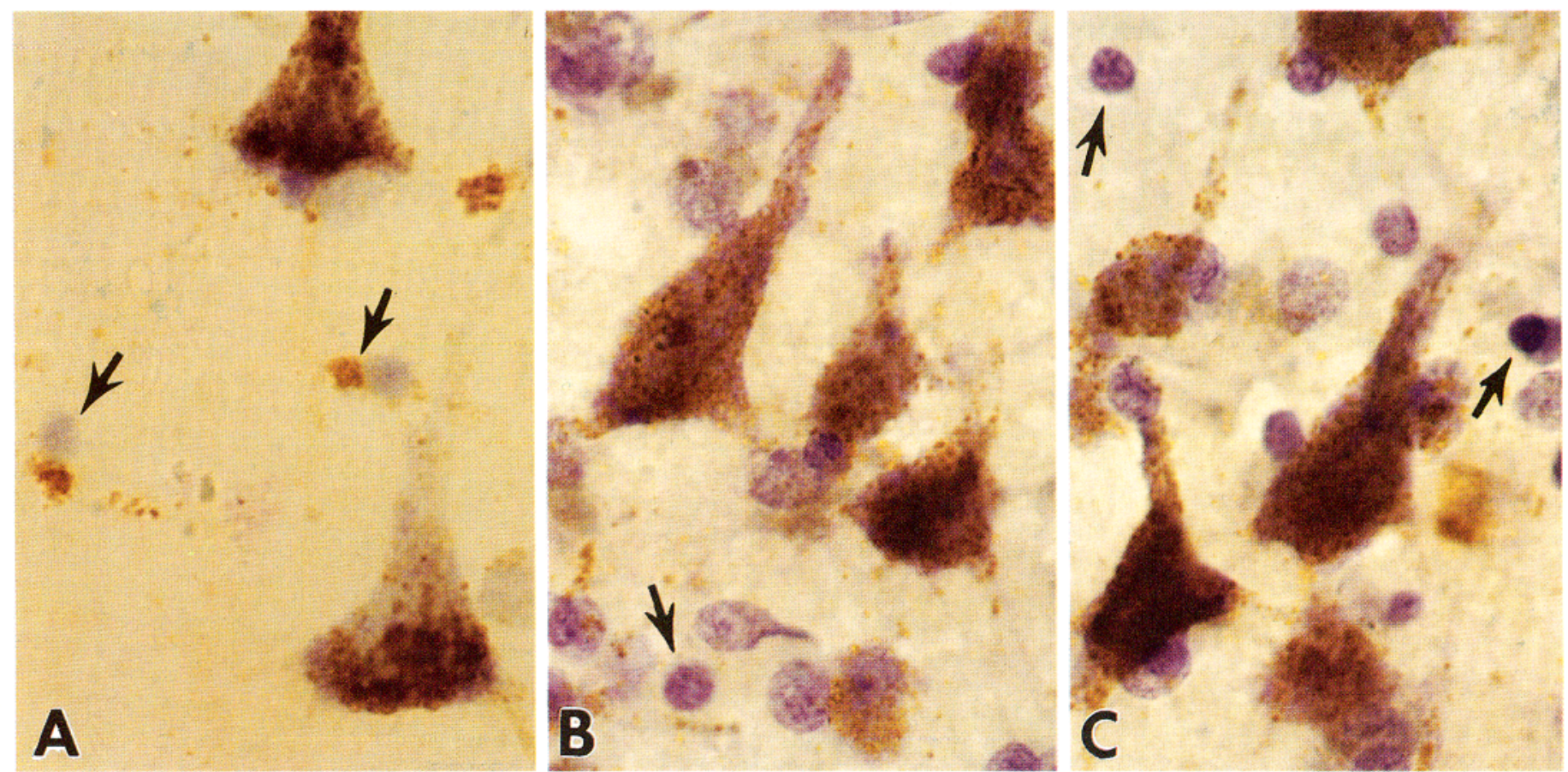

Figure 4. Hydrolase heterogeneity between neurons and glia. Hydrolase-positive intracellular compartments are more abundant in neurons compared with glia and contain a distinct complement of acid hydrolases. Similar to neurons, the lysosomal protease Cat $\mathrm{D}$ is present within glial lysosomes $(A$, arrows). Unlike cortical pyramids, however, glia do not exhibit either Cat B $(B$, arrow)- or $\operatorname{HEX}(C$, arrows)-immunoreactive lysosomes. $A-C$, $3600 \times$. 
demonstrated using secondary antibodies conjugated directly to fluorescein isothiocyanate (FITC) or tetrarhodamine isothiocyanate (TRITC) fluorophores, or indirectly to streptavidin-Texas Red. These sections subsequently were viewed with the epifluorescence optics of a Leitz Diaplan equipped with specific dichroic filters for FITC and TRITC Microscopic fields were inspected with a $100 \times$ fluotar lens (1.32 NA). A Dege-MTI SIT-68 video camera interfaced with a DSP-100 signal processor (Dege-MTI, Michigan City, IN) was used to amplify the intensity of the fluorescent image. The manual mode of a DSP-100 signal processor was used to calibrate the black, $\mathrm{kV}$, and gain settings of the camera and to optimize the visualization of each fluoroprobe. For double-labeled tissue, a single 0 set of signal processor parameters was derived that optimized the imaging requirements of each field viewed sequentially with the respective dichroic filters.

Digital confocal image analyses. High-resolution images of single- and double-labcled neurons were vicwed at high magnification using digital confocal microscopy. Images were made from representative neurons that displayed Cat D-labeled fluorescence relative to lipofuscin autofluorescence and both Cat D and MPR fluorescence. Digital images were obtained by using the same epifluorescent optics and video camera system described above, interfaced with a $\mathrm{Z}$-axis drive stage controller and an Apple Macintosh Quadra-950 computer with ONCOR-IMAGE processing software (ONCOR, Gaithersburg, MD). High magnification digitized images of representative neocortical layers III or $V$ pyramidal neurons were obtained, and a Z-series stack of images through the depth of an individual cell was acquired using $3 \mu \mathrm{m}$ step intervals through consecutive focal planes. Each captured image in a Z-series stack was saved as a 512 $\times 5128$-bit pixel image file. For each single- and double-labeled neuron, two Z-series stacks were generated with FITC and TRITC filters, respectively. Parallel pairs of stacks were processed with a deconvolution subroutine of the BDS-IMAGE software that mathematically reduces image distortion effects produced by fluorescent background flare. From each pair of deconvolved Z-series stacks, images displaying the colocalization of each fluoroprobe with a given cell were generated using the Multicolor Registration subroutine (BDS-IMAGE software).

Ultrastructural analyses. Sections for ultrastructural analyses were processed by a pre-embedding staining technique (Cataldo et al., 1991) Reacted and unreacted tissue sections were postfixed in aqueous $1 \%$ osmium tetroxide for $45-60 \mathrm{~min}$ at $23^{\circ} \mathrm{C}$, rinsed in $0.1 \mathrm{M}$ cacodylate buffer, pH 7.4, dehydrated through a series of ethanol, and embedded in Quetol 653 resin for $72 \mathrm{hr}$ at $60^{\circ} \mathrm{C}$. Semithin sections of immunostained material were cut at $0.75-1.0 \mu \mathrm{M}$ and stained with $1 \%$ toluidine blue. Ultrathin sections were placed on uncoated, 200 or 300 mesh copper grids. Grids containing immunostained material were not poststained.

Morphometric analyses. Paraffin sections from the prefrontal cortices, hippocampi, and cerebelli of nine control brains and nine age-matched Alzheimer's disease brains were immunostained in tandem under identical experimental conditions using anti-Cat D antiserum. It should be noted that the background staining intensities between Alzheimer's disease and control sections were comparable in all cases and that all neurons counted were intact. These sections were then counterstained with cresyl violet (Nissl stain) for definition of the cytoarchitecture in individual sections and for cell size analyses. Small, medium, and large pyramidal neurons from cortical laminae III and V (area 10 according to Brodmann's nomenclature) were selected at random. The cross-sectional area, number of lysosomes, and lysosomal density (area divided by lysosome number) were analyzed for each neuron using the Bioquant System IV morphometry soltware package ( $R$ \& M Biometrics, Nashville, TN) at $1000 \times$ magnification. Lysosome counts were made by direct inspection in a single plane of focus. To measure cross-sectional areas, a Zeiss Axioskop with a low-light video camera attachment was used to capture and display high resolution images using a Targa frame grabber. Neurons were isolated and outlined using a Summagraphics digitizing tablet. For each brain, 25 neurons were assessed within several fields from neocortical layers III and V, the CA2 field of the hippocampus, and the Purkinje cell layer of the cerebellum. Morphometric analyses were per- formed by several individuals, and in some instances groups of 25 neurons were analyzed blindly by each person in a section chosen at random as a control for internal bias and to ensure that counts were reproducible. A total of 450 neurons from both the control and the Alzheimer's disease cases were analyzed. For statistical comparisons based on cell size, each neuron was assigned to one of three groups on the basis of a real diameter: $0-150,151-225$, and $>225 \mu \mathrm{m}^{2}$. Statistical computations were performed using Student's $t$ test.

\section{RESULTS \\ The endosomal-lysosomal system of normal pyramidal neurons}

In normal neocortex and hippocampus from control brains, Cat D, Cat B, and HEX antibodies exclusively labeled intracellular granules of heterogeneous size, which were especially numerous in neuronal perikarya and proximal dendrites (Fig. 1). Three distinct hydrolase-containing compartments of the endosomal and lysosomal system were discriminated by additional light and immunoelectron microscopic analyses. Double-immunofluorescence cytochemistry with antibodies to Cat D and the $280 \mathrm{kDa}$ MPR, a marker of late endosomes and shuttle vesicles from the transGolgi network to the endosome (Sahagian, 1984; Brown et al., 1988; Kornfeld, 1992), distinguished subpopulations of mature lysosomes (Cat D-positive, MPR-negative) and late endosomes (MPR- and Cat D-positive) (Fig. 1). The latter displayed the typical perinuclear distribution characteristic of late endosomes in non-neural cells (Sahagian, 1984; Brown et al., 1988; Kornfeld, 1992). Immunoelectron microscopic analysis of pyramidal neurons distinguished $100-400 \mathrm{~nm}$ vacuolar compartments corresponding to lysosomes and late endosomes from lipofuscin granules, which were characterized as immunopositive $0.5-1.5 \mu \mathrm{m}$ vesicles containing varying amounts of lipid and pigment matrix components (Fig. 2). Intermediate structures reflecting stages in the evolution of mature lysosomes into lipofuscin granules were also seen (Fig. 2). To establish the proportions of lysosomes and lipofuscin granules in pyramidal neurons, we localized Cat D immunoreactivity, identified by streptavidin-Texas Red histofluorescence, in relation to lipopigment autofluorescence, a commonly used index of lipofuscin content. Confocal microscopic imaging of the two fluorescent sources in neocortical pyramidal neurons showed that lipofuscin granules containing the bulk of the lipopigment were a minor percentage of the total acid hydrolase-containing structures in adult human pyramidal neurons (Fig. 3).

Hydrolase-containing compartments in neurons were more numerous than in glial cells and displayed an enzyme composition distinct from that in glia. Cat $\mathrm{D}$ antibodies immunostained both glia and neurons (Fig. 4). HEX and Cat B were abundant in neurons but were barely detectable in glial cells (Fig. 4), whereas Cat $\mathrm{H}$ and $\mathrm{Cat} \mathrm{G}$ were identified in astrocytes but not in neurons (Cataldo et al., 1991). The number of lysosomes per volume or cross-sectional area of perikaryal cytoplasm, determined morphometrically, varied within a relatively small range among populations of pyramidal neurons in the neocortex or hippocampus (CA2, CA3) (see Fig. 6).

Figure 5. Lysosomal abnormalities in at-risk neurons from Alzheimer's disease brain. Pyramidal neurons in the prefrontal cortex $(A, B)$ and hippocampus $(C, D)$ of normal human brain $(A, C)$ contain numerous endosomal and lysosomal compartments (arrows) immunolabeled with antibodies against the protease Cat D. Early alterations of the endosomal-lysosomal system are prominent in otherwise normal-appearing at-risk neurons from Alzheimer's disease brains $(B, D$, arrows $)$ and include increased numbers of hydrolase-containing compartments, particularly with the cell soma. The arrowheads in $\mathrm{B}$ indicatc deposits of Cat $\mathrm{D}$ in the extraccllular space that reflct the rclease of acid hydrolases from acidic vacuolar compartments of degenerating neurons and/or neuritic processes. $A-D, 1200 \times$. 

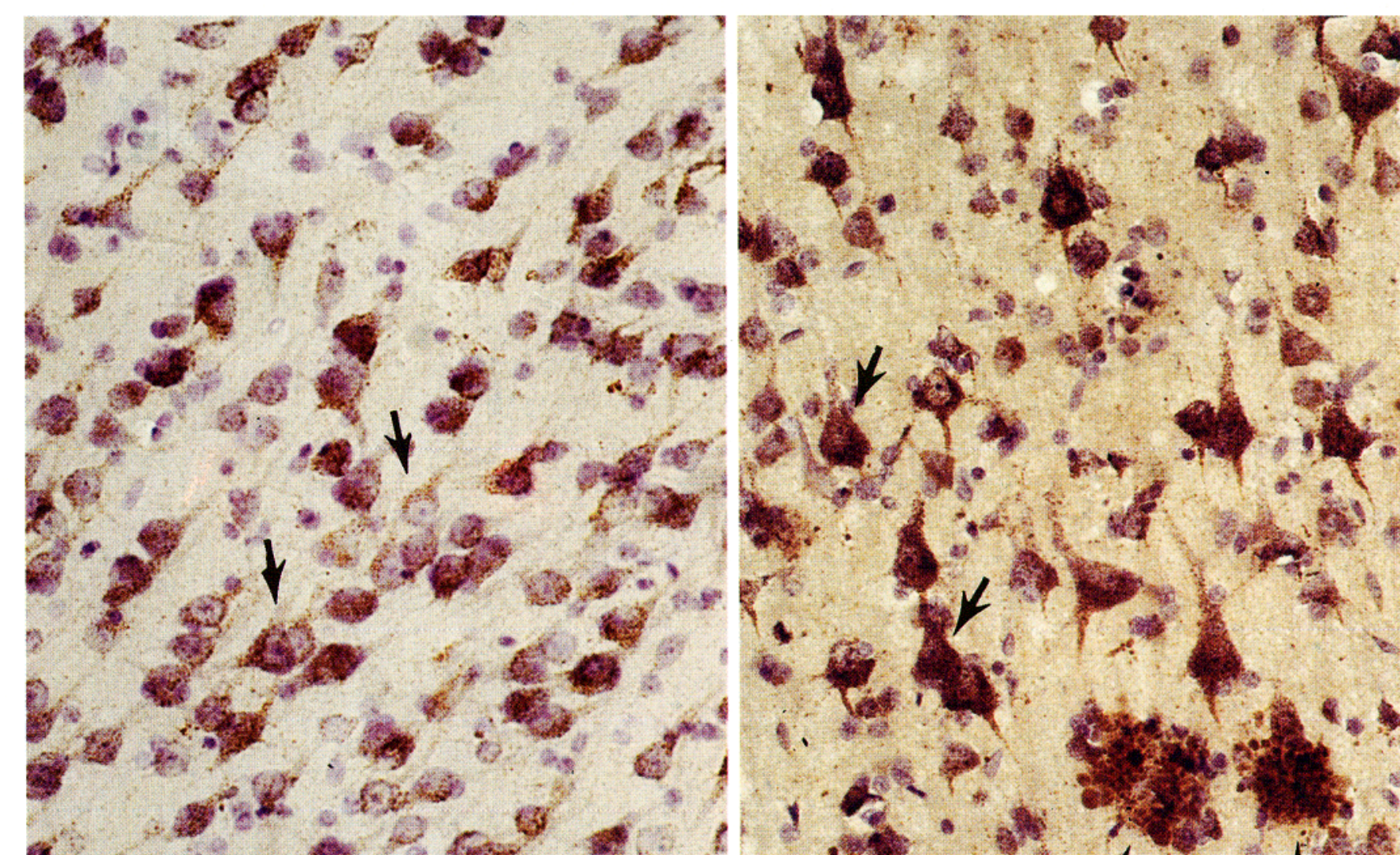

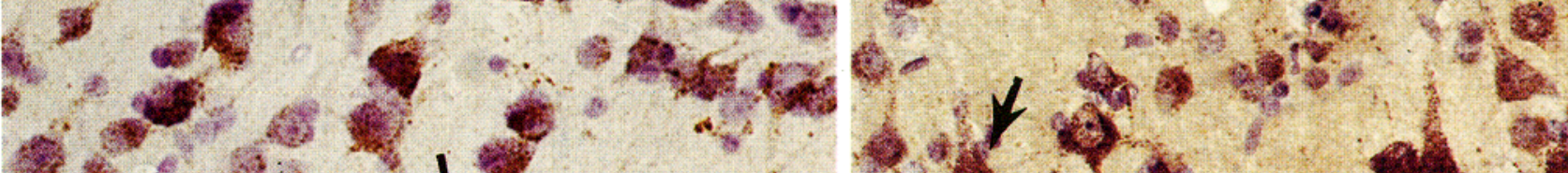

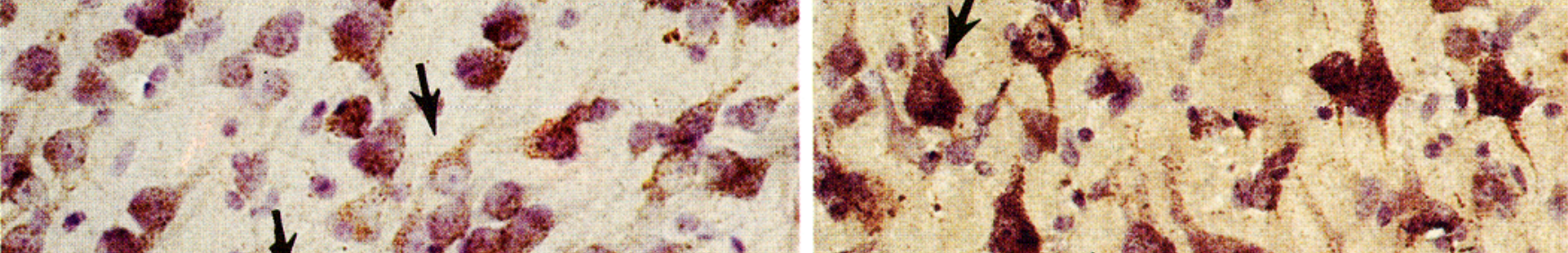

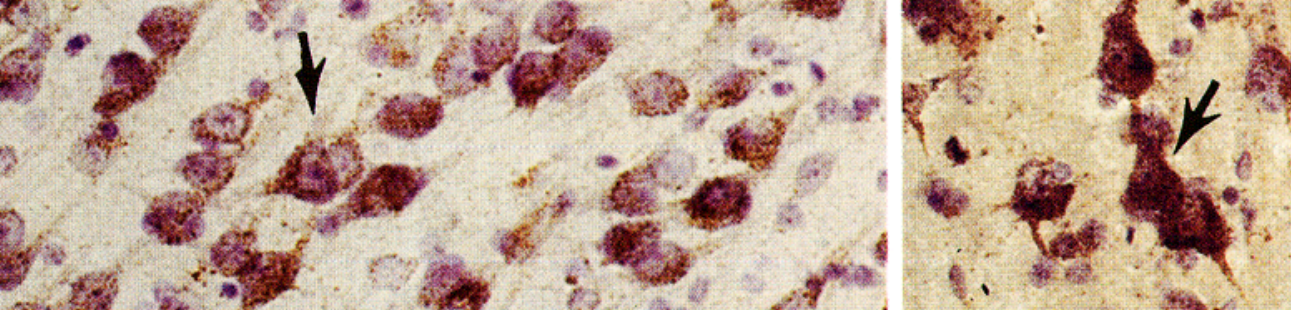

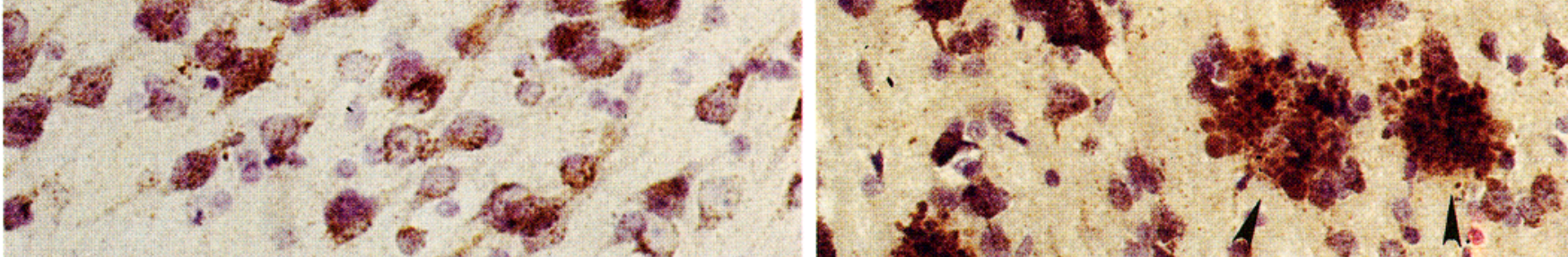

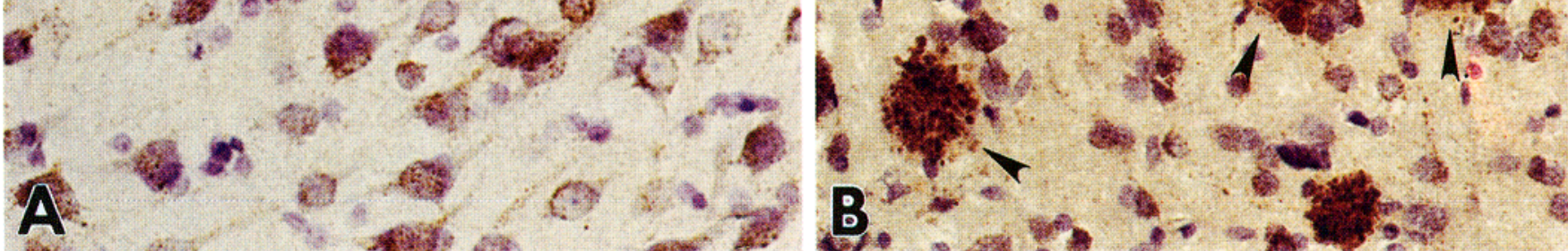

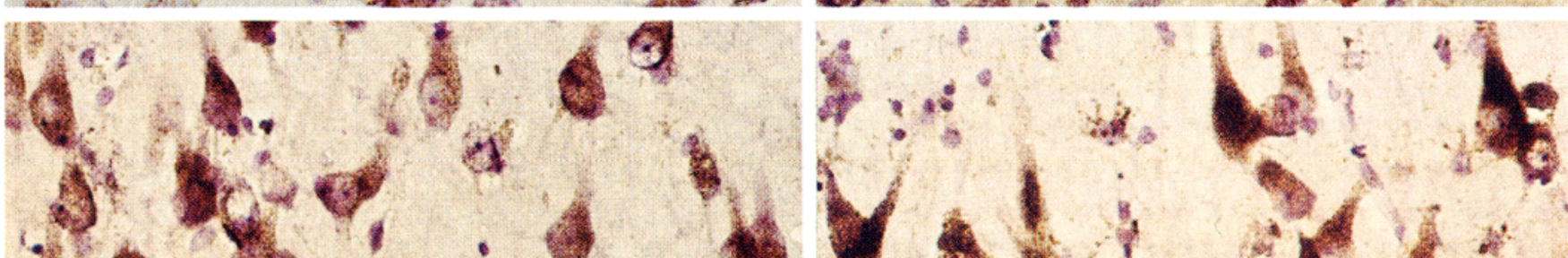

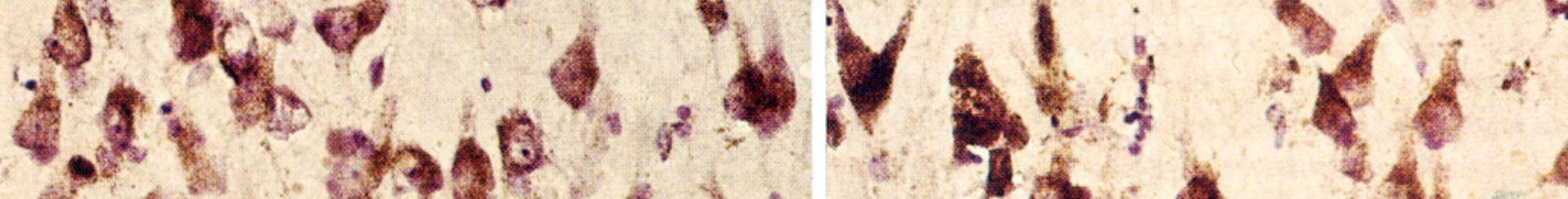

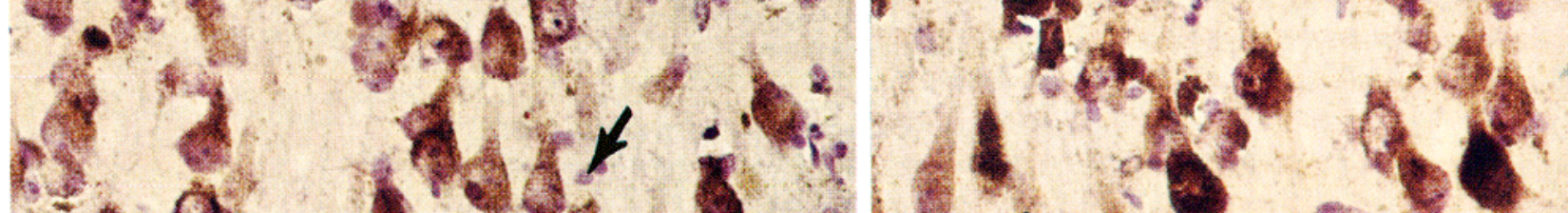<smiles>[13CH]=[AsH2]</smiles>

(a) 920

a.

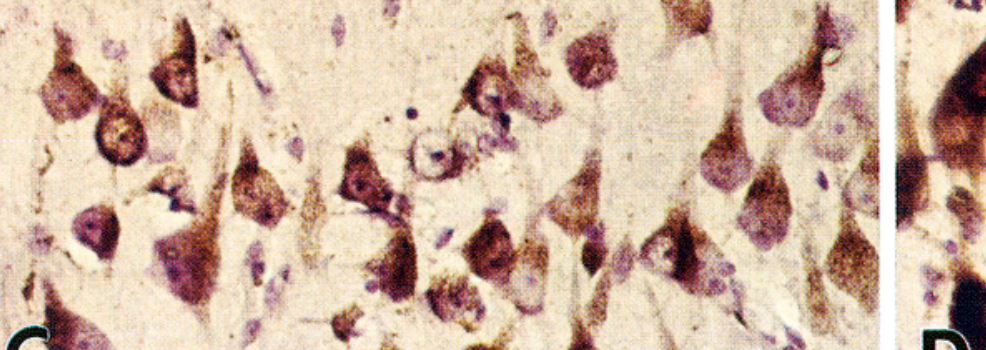
d -2.21 o

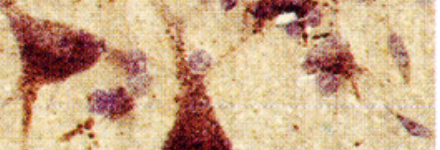
- 


\section{Endosomal-lysosomal abnormalities of pyramidal neurons in Alzheimer's disease}

Cell loss in all cortical laminae and in the hippocampus of Alzheimer's disease brains was evident by Nissl staining and from the reduced numbers of hydrolase-positive neurons. The remaining pyramidal neurons exhibited varying degrees of increased hydrolase immunoreactivity compared with their counterparts in age-matched control brains, which stained relatively uniformly (Fig. 5). Immunoreactive lysosomes accumulated prominently at the basal pole of the soma (Fig. 5), often distorting the pyramidal shape of the cell and distending the axon hillock. To estimate the prevalence of pyramidal neurons exhibiting an abnormal endosomal-lysosomal response, we determined by computerassisted morphometry the number and density of immunoreactive lysosomes in individual pyramidal neurons from nine Alzheimer's disease brains and nine age-matched control brains immunostained under identical conditions with anti-Cat D antiserum (Fig. 6). More than $90 \%$ of the pyramidal neurons in lamina III of the neocortex in Alzheimer's disease brains displayed a number and density of hydrolase-positive compartments that were more than two SD higher than the mean values for control neurons of similar size. Endosome-lysosome increases ranged as high as eightfold above the normal mean density and averaged threefold higher than controls. Abnormalities of comparable magnitude were also seen in the majority of pyramidal cells in lamina V. Similarly, in CA2 and CA3 of the hippocampus, $80-93 \%$ of the pyramidal cells contained abnormally high numbers of hydrolase-positive compartments ( $2 \mathrm{SD}$ above a control mean of $50 \pm 15$ ), ranging twoto sevenfold higher in CA2 (average 2.5-fold) and two- to fourfold higher in CA3 (average 1.75-fold), a region that is less vulnerable to degeneration in Alzheimer's disease than CA1 and CA2. Neuronal pyramids of the $\mathrm{CA} 2$ region of the hippocampus exhibited Cat $\mathrm{D}$ densities two SD above control mean $(0.17 \pm 0.02)$. These differences were minimum estimates of the abnormal hydrolase expression because the hydrolase-positive organelles were also larger in Alzheimer's disease brains. Pyramidal neurons in every size class were affected to approximately the same extent. The increased lysosome density could not be attributed to neuronal atrophy because the average cross-sectional areas of neurons from Alzheimer's disease brain were not statistically different from those of controls.

Confocal microscope images of lipofuscin autofluorescence and Cat D immunofluorescence (Fig. 3) demonstrated that in most cells lipofuscin granules accumulated to a smaller extent than the more functionally active endosomal and lysosomal compartments. Antiserum directed against a precursor form of Cat D, Pro-Cat D (known to be present in late endosomes and to some extent in early endosomes) (Erickson and Blobel, 1983; Lemansky et al., 1987; Riederer et al., 1994); predominantly immunolabeled a population of distinct, perinuclear vacuoles (Fig. 7). At-risk neurons from Alzheimer's disease brains exhibited a qualitative increase in the number of these Pro-Cat D-positive vacuolar compartments compared with the numbers detected in age-matched control brains (Fig. 7).

Most neuronal perikarya that displayed very prominent endosomal-lysosomal system alterations exhibited no overt degeneration by Nissl or neurofibrillary pathology by thioflavin or silver staining (Fig. 8). Moreover, in ultrathin sections of the immunostained tissue, ultrastructural inspection of organelles in selected hydrolase-laden neurons revealed no dilatation of the endoplasmic reticulum and Golgi saccules, nuclear clumping, detached or scattered ribosomes, blebbing, or swelling irregularities in the plasmalemma or condensed mitochondria (Fig. 8).

\section{Endosomal-lysosomal abnormalities in less vulnerable neuron populations}

Neurons from less severely affected regions of Alzheimer's disease brains displayed similar, but less marked, lysosomal system abnormalities (Fig. 9). The numbers of hydrolase-positive lysosomes were clearly increased in some neurons from the striatum, thalamus (Nixon et al., 1992; Cataldo et al., 1995), and medulla (Burke et al., 1995). The accumulation of organelles at the basal pole of the cell body resembled the pattern in affected neocortical neuronal populations. Most affected neurons displayed no neurofibrillary pathology by silver staining or chromatolytic changes by Nissl staining. Finally, we quantitated Cat D-positive compartments in Purkinje cells, a population of neurons considered to bc affected minimally in Alzheimer's disease. Normal Purkinje cells exhibited a slightly lower density of endosomes/lysosomes than pyramidal neurons (Figs. 6, 9) and a greater degree of variation in endosome-lysosome number among cells, possibly reflecting the metabolic heterogeneity known to exist in this cell population. In contrast to the situation for pyramidal cells, average endosome/ lysosome density in Purkinje cells in Alzheimer's disease brains did not differ significantly from that in control brains. A small percentage of cells $(\sim 5 \%)$ did display significantly higher numbers of Cat D-positive compartments, confirming qualitative observations (Figs. 6, 9) (Nixon et al., 1992, 1993; Cataldo et al., 1994, 1995).

\section{DISCUSSION}

\section{The endosomal-lysosomal system of mature neurons}

In these studies we have identified the major acid hydrolase compartments in normal adult human pyramidal neurons and have distinguished functionally diverse subpopulations that include late endosomes, mature lysosomes, and lipofuscin granules. The former two compartments represent the final common pathway of endosomal and autophagosomal vesicular trafficking, and their numbers reflect the level of lysosomal system activation that may result from changes in either endocytic (heterophagic) or autophagic activity (Gordon and Seglen, 1988; Gordon et al., 1992; Nixon and Cataldo, 1995). By contrast, postlysosomal compartments such as lipofuscin, which arise from the progressive accretion of indigestible residues in lysosomes, serve as a morphological indicator of lysosomal degradative efficiency. Their accumulation most often reflects lysosomal dysfunction or modifications of membrane and protein substrates that reduce their digestibility within the lysosome (Brizzee et al., 1975; Siakotos, 1975). We observed that normal human pyramidal neurons have a well developed and highly variegated lysosomal system, consistent with the essential role of this system in maintaining huge cytoplasmic volumes and large expanses of membrane surface area. Mature lysosomes were considerably more numerous than endosomes and lipofuscin, even in older adults. The strikingly different enzyme composition of lysosomes in neurons and glia, supported by some biochemical observations (Friede, 1965; Bowen et al., 1974), indicates that the relative expression of acid hydrolases in different neural cell types is tailored for the particular substrates encountered. Lysosomal processing of the same protein in different brain cell types might be expected, therefore, to generate distinct sets of proteolytic fragments along the pathway to complete degradation.

Our morphometric analyses showed that normal neurons of a 


\section{Prefrontal Cortex}
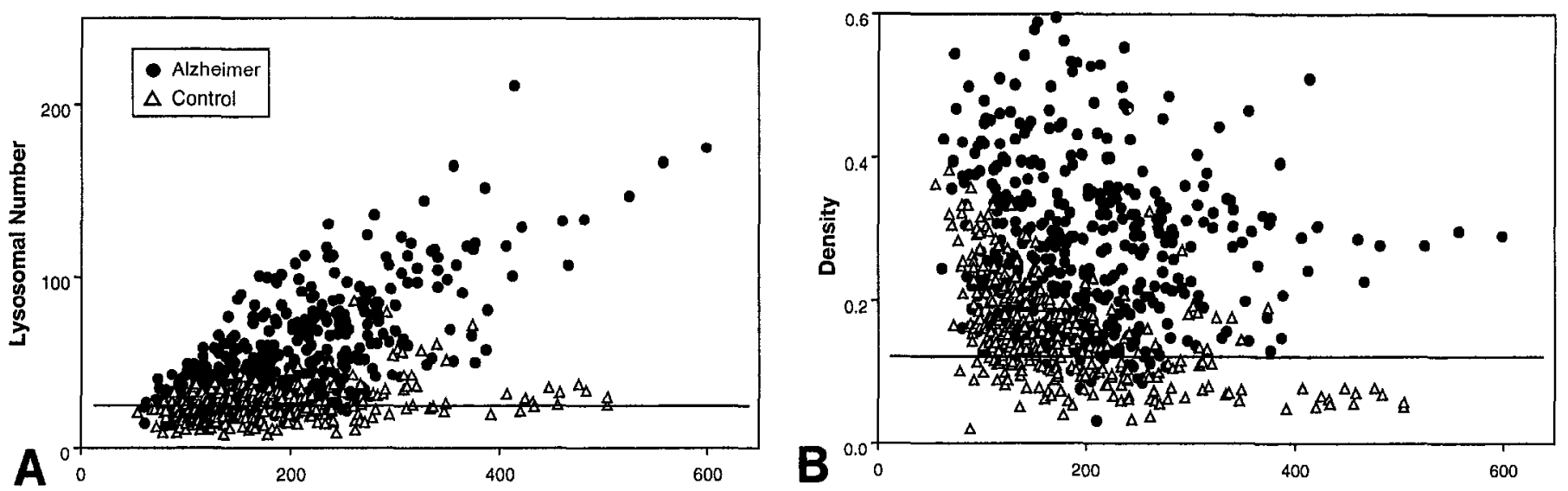

Hippocampus CA2
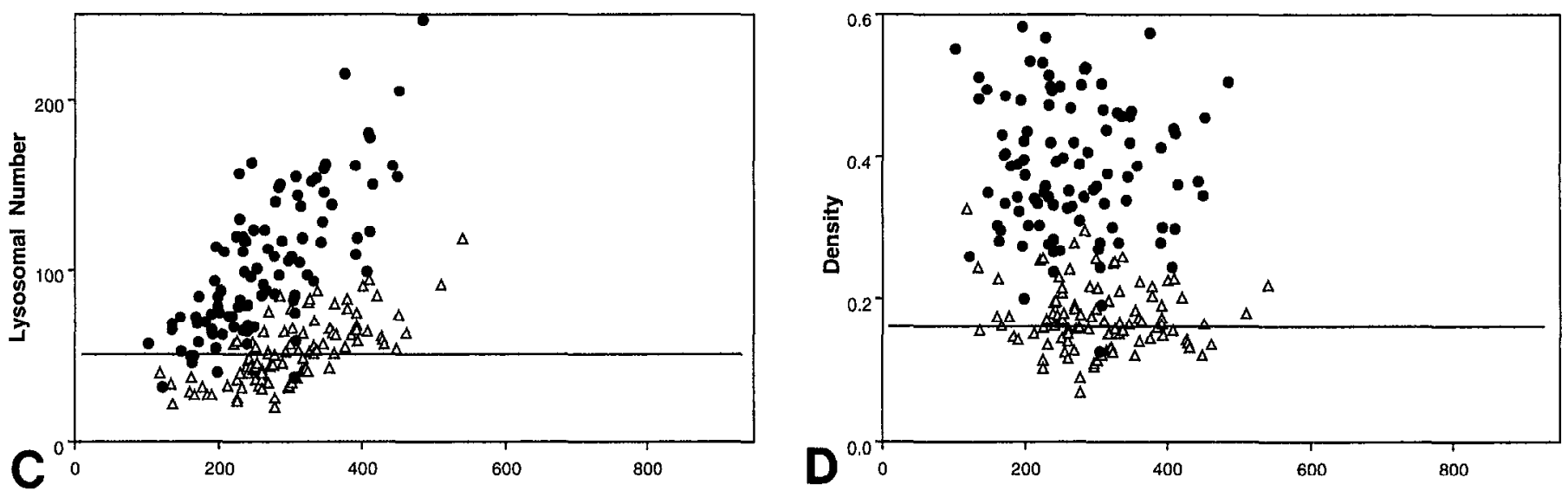

\section{Cerebellum}

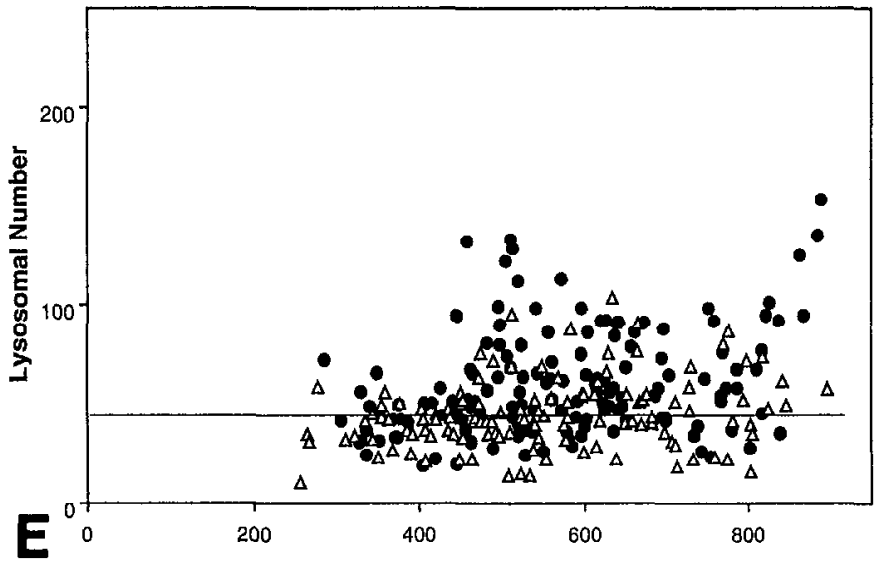

Area $\left(\mu \mathrm{m}^{2}\right)$

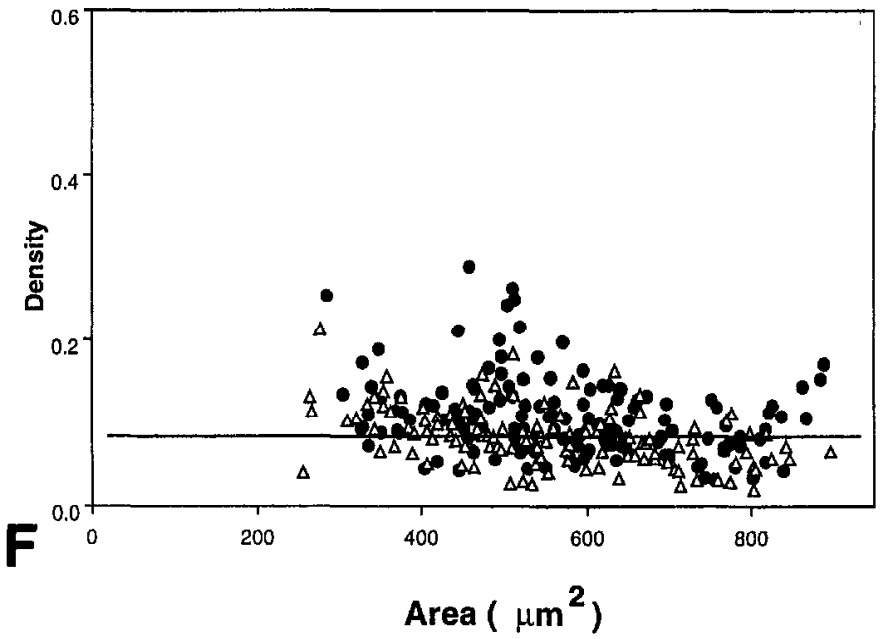

Figure 6. Morphometric analyses of Cat D positive compartments in control and Alzheimer's disease brains. Quantitative morphometric analyses from sections of the prefrontal cortex $(A, B)$, the CA2 field of the hippocampus $(C, D)$, and Purkinje cells of the cerebellum $(E, F)$ revealed that lysosomal abnormalities are widespread within the most severely affected neuronal populations (cortical and hippocampal pyramids) of Alzheimer's disease brains $(A-D)$. The majority of cortical pyramids in laminae III and V and the hippocampal CA2 field of Alzheimer's disease brains (O) exhibit increased Cat D-containing endosome/lysosome numbers $(A, C)$ and densities $(B, D)$ per cross-sectional area compared with age-matched controls $(\triangle)$. In contrast to the significant differences in the numbers and densities of Cat D-positive compartments displayed by these cell types in Alzheimer's versus control cases, the average endosome/lysosome number and density in Purkinje cells of the cerebellum $(E, F)$ from the same Alzheimer's disease individuals did not differ significantly from those displayed by controls. 


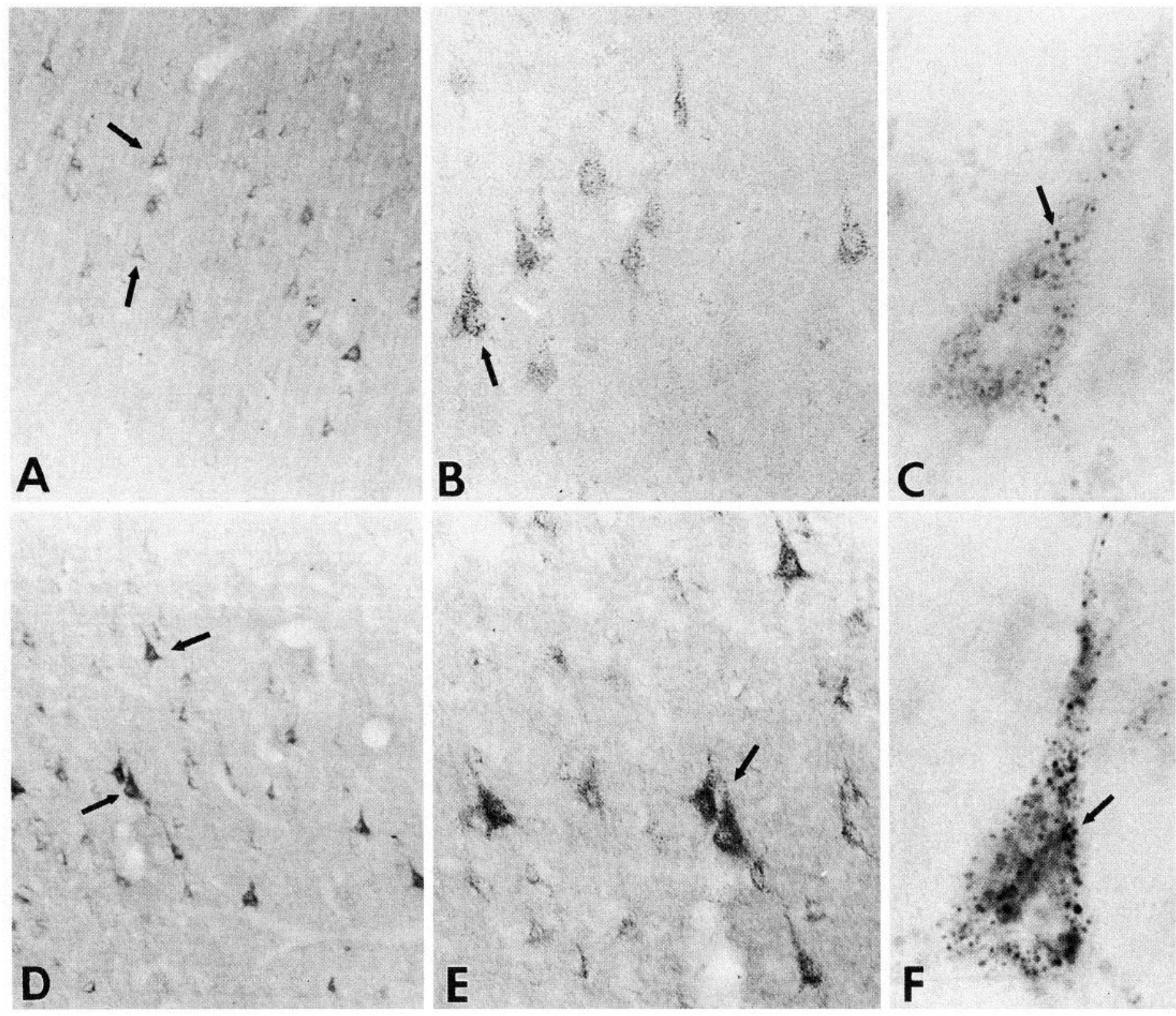

Figure 7. Distribution of Pro-Cat D in control and Alzheimer's disease brains. In control brains, the intracellular localization of proforms of Cat D was identified within membrane-bound immunoreactive endosomal compartments $(A-C$, arrows $)$. Abnormalities in the levels of Cat $\mathrm{D}$ proforms were widespread within at-risk populations of neurons from layers III and V of Alzheimer's disease brains $(D-F$, arrows). Higher magnification photomicrographs of a prefrontal pyramidal neuron from an Alzheimer's disease brain $(F)$ shows increased numbers of immunolabeled vacuolar compartments compared with the same cell types from a representative age-matched control $(C) . A, D, 400 \times ; B, E, 1000 \times ; C, F, 4000 \times$.

given type regulate their lysosome numbers within a fairly narrow range. The number of hydrolase-containing compartments correlated closely with perikaryal size, which in turn is a rough index of axonal length and total axoplasmic volume (Ho et al., 1992). Their density in perikarya expressed as number/cross-sectional area was twofold higher in small pyramidal neurons than in large ones; however, when expressed as number/estimated perikaryal volume, lysosome density varied relatively little among neurons of the same type. As the final common pathway of endocytic and autophagocytic traffic and other protein processing rates, the endosomal-lysosomal system may be influenced by changes in the rate of endocytic activity and membrane turnover (Trowbridge, 1991), the rate of protein synthesis (Strous et al., 1988), and the general metabolic rate and functional activity of the neuron. Whereas nonlysosomal degradation occurs at a fairly constant rate of $1-1.5 \%$ in most cells, the contribution of the lysosomal system may vary from nearly 0 to $4 \%$ of the total protein of the cell per hour, depending on nutritional and hormonal conditions (Seglen and Bohley, 1992) or circadian rhythms (Bhattacharya and von Mayersbach, 1976). For these reasons, lysosomal system activity potentially can serve as a sensitive and useful index of cellular function and dysfunction, reflecting metabolic shifts and structural reorganization in response to changing conditions.

\section{Endosomal-lysosomal alterations are an early intracellular event in Alzheimer's disease}

The endosomal-lysosomal system in neurons of the Alzheimer's disease brains was prominently altered. These changes were 

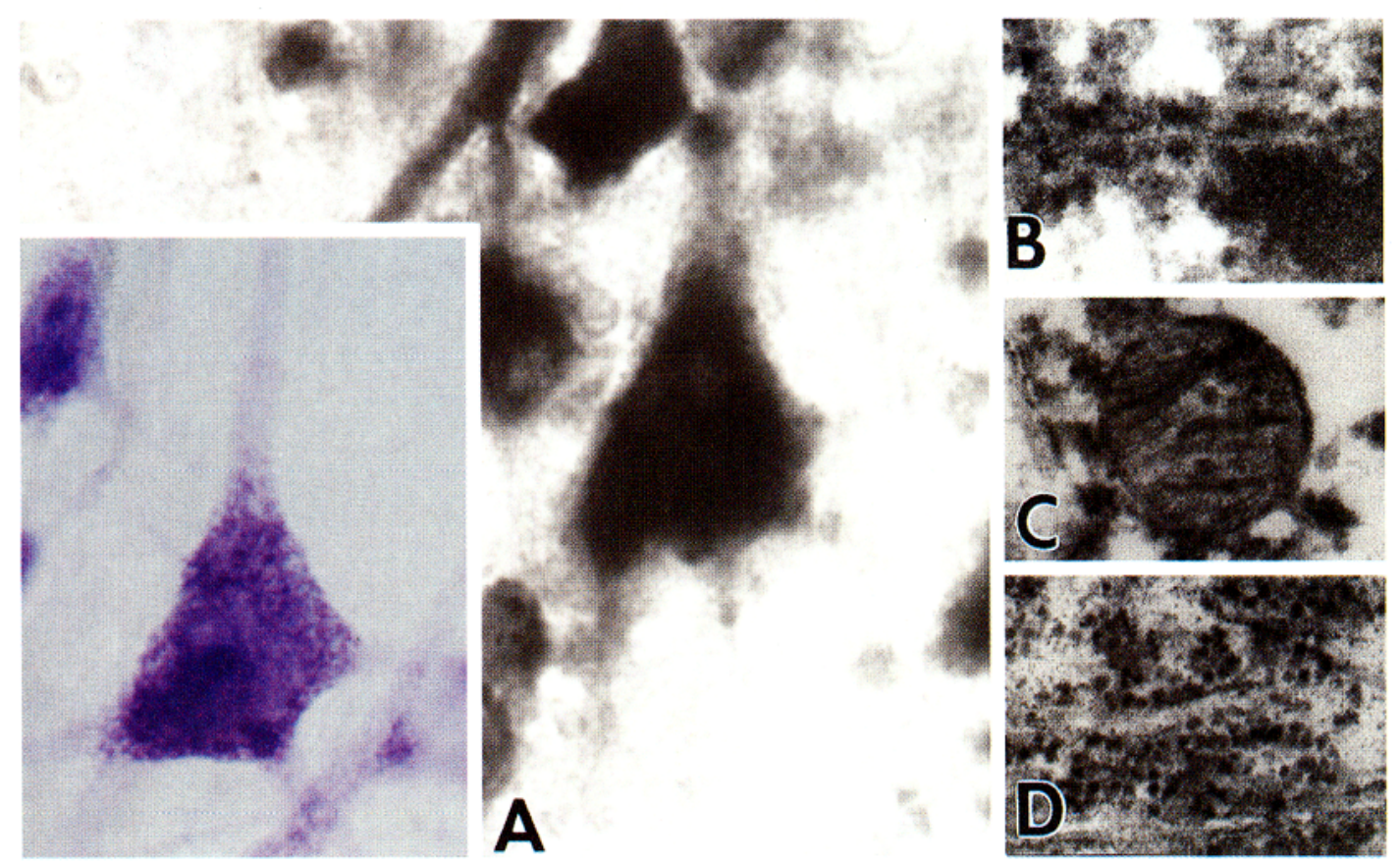

Figure 8. Lysosomal abnormalities are an early event in at-risk neurons from Alzheimer's disease brains. Increased numbers of Cat D-containing endosomal and lysosomal compartments $(A)$ are prominent in the majority of at-risk pyramidal neurons and precede histological evidence of atrophy/chromatolysis by Nissl stain $(A$, inset). The absence of atrophic change in the nuclear membrane $(B)$, mitochondria $(C)$, and rough ER $(D)$ is confirmed by electron microscopic inspection of the same neuron as in $A$. $A, A$ inset, $4000 \times ; B-D, 50,000 \times$.

among the earliest manifestations of a metabolic compromise, as evidenced by the observation that nearly all pyramidal neurons in vulnerable prefrontal and hippocampal regions of Alzheimer's disease cases exhibited abnormally high densities of lysosomes, even though only a small percentage of these neurons exhibited neurofibrillary tangles or atrophy. In representative cells within these populations, lysosomal system alterations were the only structural abnormalities detectable in the perikaryon at the light and electron microscope levels, although alterations of axonal projections and dendritic arborizations cannot be excluded. These findings agree with earlier observations that pyramidal neurons unaffected by neurofibrillary tangles seemed normal with respect to the area occupied by the nucleus, nucleolus, mitochondria, smooth endoplasmic reticulum, and rough endoplasmic reticulum (Mann and Sinclair, 1978). Recently, subsets of at-risk neurons that are susceptible to neurofibrillary tangle formation but do not contain tangles have also been shown to exhibit increased apolipoprotein E (APOE) levels (Han et al., 1994b; Einstein et al., 1995). These findings are also consistent with increased receptormediated internalization and trafficking through endosomal-lysosomal compartments (Rebeck et al., 1993). Similar endosomallysosomal alterations were detected in otherwise seemingly normal pyramidal neurons in Down's syndrome at a stage when neurofibrillary tangles are absent and only diffuse deposits of $\beta$-amyloid are seen (Nixon et al., 1993), and these changes are evident in areas devoid of A $\beta$ deposits. Moreover, endosomallysosomal alterations were also seen in neuronal populations that are not usually lost in substantial numbers in Alzheimer's disease, such as the Purkinje cells and nonpyramidal neurons of the striatum, thalamus, and inferior olive (Nixon et al., 1993; Burke et al., 1994). These changes, therefore, clearly preceded advanced cell injury and can be considered an early sign of cellular dysfunction. Abnormalities in the endosomal-lysosomal system are likely to be a common link closely related to primary etiological factors increasing susceptibility to Alzheimer's disease, such as APOE genotype (Corder et al., 1993; Strittmatter et al., 1993) and mutations associated with familial Alzheimer's disease (Goate et al., 1991; Levy-Lahad et al., 1995; Sherrington et al., 1995).

\section{Accumulation of endosomes/lysosomes reflects upregulation, not stasis, of the system}

That these findings imply an activation of lysosome biogenesis and intracellular trafficking of hydrolase-containing compartments is strongly supported by in situ hybridization studies demonstrating increased Cat D mRNA and Cat D protein expression in the same populations of neurons that display endosome-lysosome accumulation (Cataldo et al., 1995) and by immunocytochemical studies showing increases in the proforms, as well as the mature forms, of Cat D. Confocal microscopic detection of Cat D immunofluorescence and lipopigment autofluorescence in the same neuron showed that lipopigment-containing structures are a significant but still minor percentage of the total population of hydrolase-positive compartments. Hydrolase immunoreactivity, principally within late endosomes and mature lysosomes, increased to a much greater degree than lipofuscin, which reflects lysosomal system stasis or dysfunction (Swaab, 1991; Nixon and Cataldo, 1993), in agreement with previous evidence that lipofuscin is either unchanged (Mann et al., 1984) or modestly increased (Dowson, 1982) in Alzheimer's disease brains.

Given current knowledge of lysosomal system function, early activation of the endosomal-lysosomal system could be either a regenerative or an involutional response and could reflect enhanced autophagy or endocytosis (heterophagy) or both. We have suggested previously that these processes are activated by membrane injury or the need for membrane synthesis and repair resulting from cumulative aging, genetic, oxidative, and chemical factors (Nixon and 

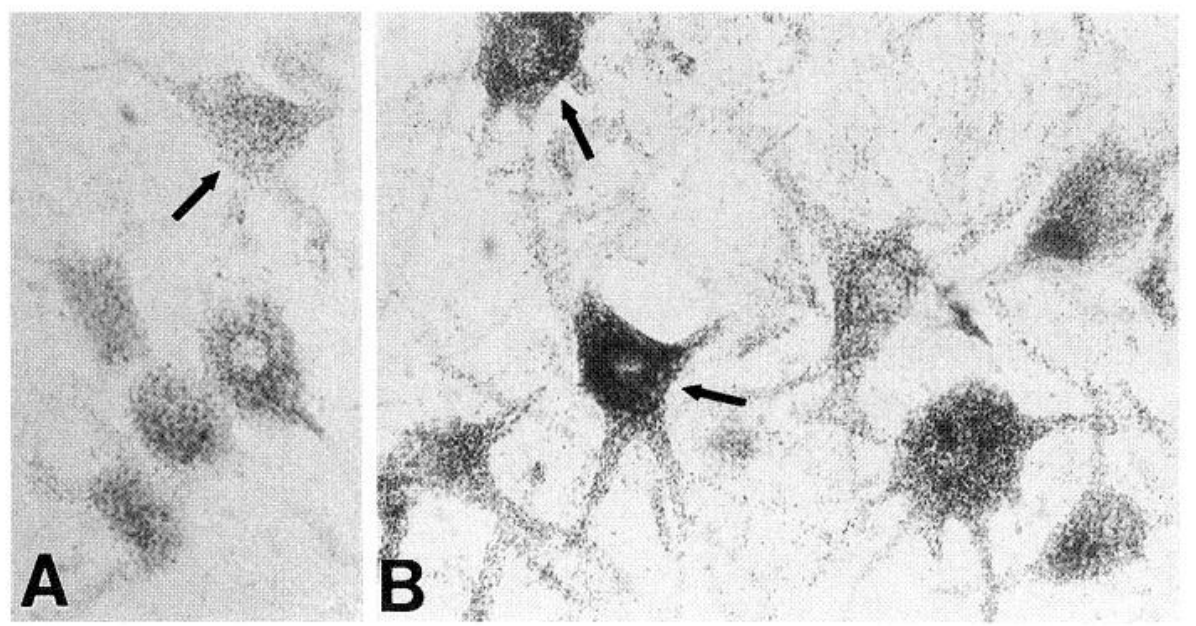

Figure 9. Acid hydrolase abnormalities in less vulnerable neuronal populations. Alterations in Cat D-containing vacuolar compartments were prominent within the several subcortical neuronal populations $(B-D$, arrows $)$ and cerebellum $(E, F$, arrows $)$ from Alzheimer's disease brains compared with the same cell types from control brains $(A, E$, inset $) . E$, Inset shows the average number of Cat D-positive compartments (arrows) in an epinephrine neuron from the medulla $(A)$ and cerebellar Purkinje cell $(E$, inset) of a normal aged control brain. In $\mathrm{Alz}$ heimer's disease brains, less severely affected neuronal populations of the medulla $(B)$, striatum $(C)$, thalamus $(D)$, and cerebellum $(E, F)$ contained moderately increased numbers of Cat B-positive endosomal/lysosomal compartments compared with controls. In the cerebellum of Alzheimer's disease brains, Purkinje cells containing levels of Cat D similar to those from control brains (thin arrow) are often found scattered among neurons containing increased intracellular levels of Cat D-immunoreactive compartments (thick arrow). $A-E, E$ inset, $3000 \times ; F, 800 \times$.
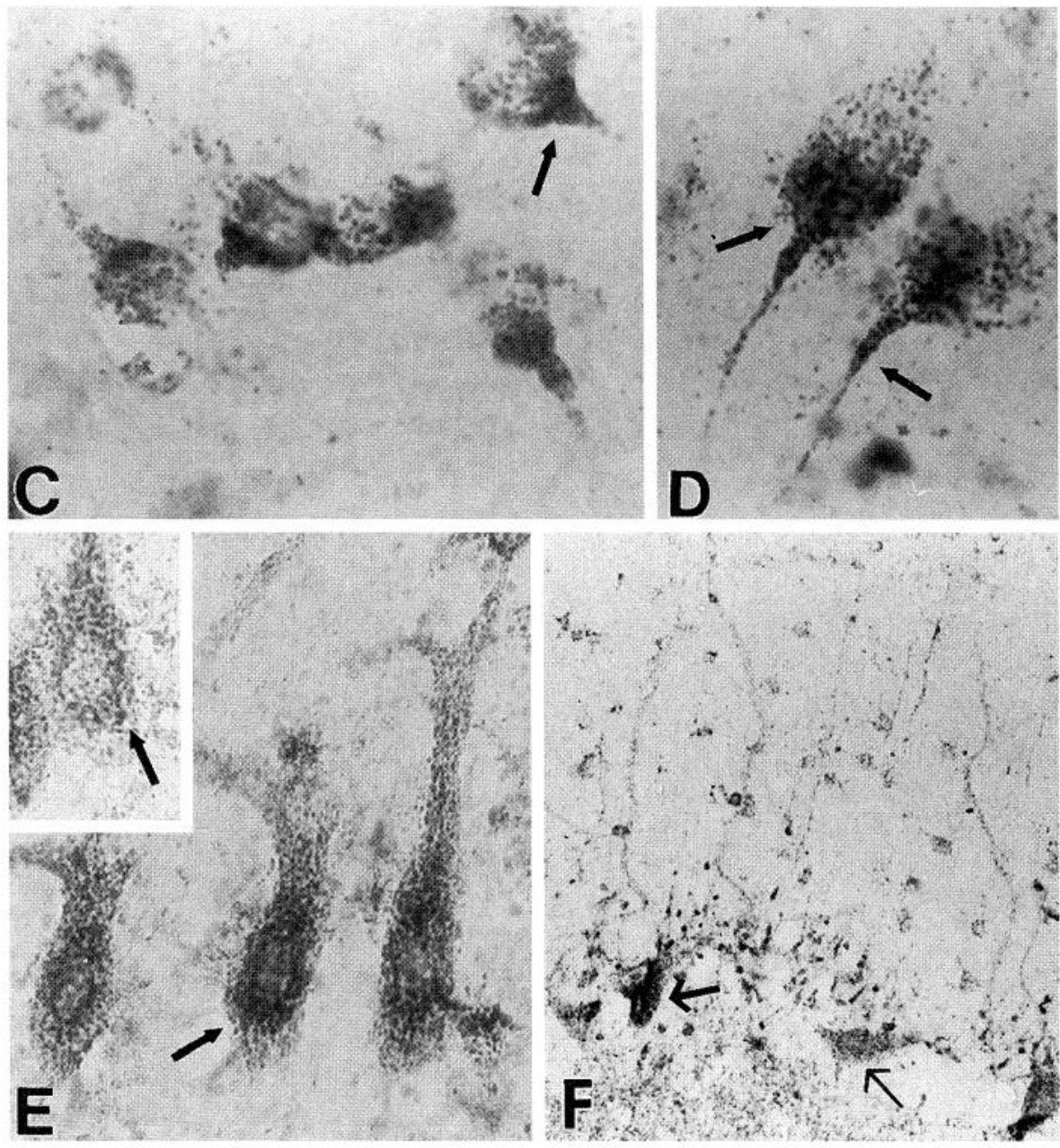

Cataldo, 1991, 1994; Nixon et al., 1992). Endosomal-lysosomal system activity has been implicated in dendrite development (Roberts and Gorenstein, 1987), in synapse formation through the elimination of some nascent synapses and stabilization and remodeling of persisting ones, and in the repair of injured axon fibers (Teuchert-Noodt et al., 1991). Because most endosomal-lysosomal system compartments undergo net retrograde transport (Gorenstein et al., 1985), changes in the lysosomal system in neuronal perikarya may be particularly sensitive to structural alterations taking place in the periphery, such as the marked synaptic degeneration/regeneration accompanying Alzheimer's disease (DeKosky and Scheff, 1990; Terry et al., 1991). In this regard, the same populations of at-risk neurons in Alzheimer's disease brains that exhibit endosomal-lysosomal alterations exhibit abnormalities in APOE content (Einstein et al., 1995). APOE is thought to be functionally important in central nervous system neuroplasticity and regeneration (Nathan et al., 1994). Altered levels of APOE in vulnerable neurons are consistent with repair/regeneration within these same cell groups. Moreover, recent findings using genetically altered APO-deficient mice (Masliah et al., 1995) suggest that abnormal APOE expression con- 
tributes to abnormal neuroplasticity (sprouting) and increased neurodegeneration in Alzheimer's disease.

\section{Relationship of intracellular and extracellular lysosomal system disturbances and Alzheimer's disease risk factors}

The abnormal endosomal/lysosomal response in most pyramidal neurons of Alzheimer's disease brains seems to be continuous, with the process resulting in the massive accumulation of lysosomes and hydrolase-positive lipofuscin in a smaller population of cells that have neurofibrillary tangles or atrophic perikarya (Cataldo et al., 1994). As these cells degenerate, similar lipofuscin aggregates are abundant in the extracellular space in association with $\beta$-amyloid deposits (Cataldo and Nixon, 1990). Cat D levels in CSF are elevated markedly relative to those in other neurodegenerative diseases (Schwagerl et al., 1995). The intracellular lysosomal abnormalities in Alzheimer's disease revealed by acidhydrolase antibodies exceed those in a survey of other degenerative conditions, including Huntington's disease, Pick's disease, multiple sclcrosis, and Crcutzfcldt-Jacob discasc (Nixon ct al., 1992; Cataldo et al., 1994). Moreover, the persistence of these lysosomal compartments in the extracellular space after neurons degenerate distinguishes this cytopathological pattern from that so far reported for any other neurodegenerative disease process (Nixon and Cataldo, 1993). Extracellular acid hydrolase deposits thus far have been observed only in the various conditions in which $\beta$-amyloid is deposited (Cataldo et al., 1991; Nixon et al., 1993; Villanova et al., 1993; Haas and Sparks, in press).

Because amyloid precursor protein is metabolized in lysosomes (Golde et al., 1992), increased or abnormal lysosomal turnover of amyloid precursor protein (APP) or its mutant forms (Mullan and Crawford, 1993) might be expected to accelerate the generation of metabolic intermediates of APP, some of which may be amyloidogenic (Caporaso et al., 1992; Estus et al., 1992) and/or neurotoxic (Yankner et al., 1989; Neve et al., 1992). Although the in vivo sitcs of $\mathbf{A} \beta$ generation in normal and Alzhcimcr's discasc brains are not fully resolved, soluble forms of $A \beta$ 1-40 and 1-42, 43 are secreted by some cell lines in vitro, and indirect evidence implicates an endosomal or late Golgi compartment in their formation (Haass et al., 1992, 1993; Buscaglio et al., 1993; Koo and Squazzo, 1994). Both of these compartments normally harbor low levels of certain lysosomal hydrolases and might be expected to have higher levels when hydrolase expression is markedly upregulated, as it is in Alzheimer's disease (Cataldo et al., 1995). Certain cathepsins satisfy important criteria for being candidate $\beta$-amyloid-generating enzymes, including a localization in appropriate compartments for $A \beta$ formation, abnormally high expression in Alzheimer's disease, and appropriate bond specificity against APP and model peptides (Dreyer, 1984; Tagawa et al., 1992; Ladror et al., 1994). APOE, another important molecule implicated in Alzheimer's disease (Corder et al., 1993; Strittmatter et al., 1993), is synthesized by astrocytes and taken up by neurons in markedly increased amounts in response to various forms of neuronal injury, presumably to provide cholesterol for new membrane synthesis and regenerative processes (Mahley, 1988; Han et al., 1994a; Benzing and Mufson, 1995). Endosomal-lysosomal system activity is essential for this function. The intracellular internalization and trafficking of APOE through endosomal-lysosomal compartments may be closely associated with the role of APOE in neuronal metabolism, particularly membrane turnover (Roses, 1994, 1995). Identification of a putative membrane protein as the product of the mutated gene on chromosome 14 causing an early-onset form of familial Alzheimer's disease (Sherrington et al., 1995) suggests the need for membrane turnover/repair as a basis for endosomal-lysosomal upregulation. Finally, normal aging, another well established risk factor for Alzheimer's disease, is accompanied by increased expression of some lysosomal proteases (e.g., Cat D, Cat B) (Matus and Green, 1987; BanaySchwartz et al., 1992) and decreased stability of the lysosomal membrane (Sawant et al., 1964), which may superimpose on more prominent, disease-related changes. Endosomal-lysosomal abnormalities, therefore, may be considered to lie at a crossroad of various etiological pathways, and an understanding of their basis may contribute to a more unified picture of Alzheimer's disease pathogenesis.

\section{REFERENCES}

Baas PW, Heideman SR (1986) Microtubule reassembly from nucleating fragments during the regrowth of amputated neurites. I Cell Biol 104:917-927.

Banay-Schwartz M, DeGuzman T, Kenessey A, Palkevits M, Lajtha A (1992) The distribution of cathepsin D activity in adult and aging human brain regions. J Neurochem 58:2207-2211.

Benzing WC, Mufson EJ (1995) Apolipoprotein E immunoreactivity within neurofibrillary tangles: relationship to tau and PHF in Alzheimer's disease. Exp Neurol 132:162-171.

Bernstein HG (1994) The many faces of lysosomal proteinase (cathepsins) in human neuropathology: a histochemical perspective. Eur J Histochem 38:189-192.

Bernstein HG, Brusziz S, Schmidt D, Wiederanders B, Dorn A (1989) Immunodetection of cathepsin $D$ in neuritic plaque found in brains of patients with dementia Alzheimer's type. J Hirnforsch 30:613-618.

Bhattacharya R, von Mayersbach H (1976) Histochemistry of circadian changes of some lysosomal enzymes in rat liver. Acta Histochem [Suppl] (Jena) 16:109-115.

Bowen DM, Flack RHA, Martin RO, Smith CB, White P, Davidson AN (1974) Biochemical studies on degenerative neurological disorders. I. Acute experimental encephalitis. J Neurochem 22:1099-1107.

Brizzee KR, Kaack B, Klara B (1975) Lipofuscin: intra- and extraneuronal accumulation and regional distribution. In: Advances in behavioural biology, Vol 16 (Ordy JM, Brizzee KR, eds), pp 463-481. New York: Plenum.

Brown WJ, Goodhouse J, Farquhar MG (1988) Mannose 6-phosphate receptors for lysosomal enzymes cycle between the Golgi complex and endosomes. J Cell Biol 103:1235-1247.

Burke WJ, Galvin NJ, Chung HD, Stoff SA, Gillespie KN, Cataldo AM, Nixon RA (1994) Degenerative changes in epinephrine tonic vasomotor neurons in Alzheimer's disease. Brain Res 661:35-42.

Burke WJ, Wessel TC, Joh TH, Schmitt CA, Chung HD, Cataldo AM, Nixon RA (1995) Defective axonal transport: a mechanism in degeneration of epinephrine neurons in Alzheimer's disease. Neurol 45[Suppl 4]:A307-A308.

Buscaglio J, Gabuzda DH, Matsudaira P, Yankner BA (1993) Generation of beta-amyloid in the secretory pathways in neuronal cells. Proc Natl Acad Sci USA 90:2090-2096.

Caporaso GL, Gandy SE, Buxbaum JD, Greengard P (1992) Chloroquine inhibits intracellular degradation but not secretion of Alzheimer's beta/A4 amyloid precursor protein. Proc Natl Acad Sci USA 89:2252-2256.

Casciola-Rosen LA, Hubbard AL (1991) Hydrolases in intracellular compartments of rat liver cells. Evidence for selective activation and/or delivery. J Biol Chem 266:4341-4347.

Cataldo AM, Barnett JL, Berman SA, Li J, Quarless S, Bursztajn S, Lippa C, Nixon RA (1995) Gene expression and cellular content of cathepsin $D$ in human neocortex: evidence for early upregulation of the endosomal-lysosomal system in pyramidal neurons in Alzheimer's disease. Neuron 14:1-20.

Cataldo AM, Hamilton DJ, Nixon RA (1994) Lysosomal abnormalities in degenerating neurons link neuronal compromise to senile plaque development in Alzheimer's disease. Brain Res 640:68-80.

Cataldo AM, Nixon RA (1990) Enzymatically active lysosomal proteases are associated with anyloid deposits in Alzheimer's brain. Proc Nat Acad Sci USA 87:3861-3865. 
Cataldo AM, Paskevich PA, Kominami E, Nixon RA (1991) Lysosomal hydrolases of different classes are abnormally distributed in brains of patients with Alzheimer's disease. Proc Natl Acad Sci USA 88:10998-11002.

Cataldo AM, Thayer CY, Bird ED, Wheelock TR, Nixon RA (1990) Lysosomal proteinase antigens are prominently localized within senile plaques of Alzheimer's disease: evidence for a neuronal origin. Brain Res 513:181-192.

Corder EH, Saunders AM, Strittmatter WJ, Schmechel DE, Gaskel PC, Small GW, Roses AD, Haines JL, Pericak-Vance MA (1993) Gene dose of apolipoprotein E type 4 allele and the risk of Alzheimer's disease in late onset families. Science 261:921-923.

DeKosky ST, Scheff SW (1990) Synapse loss in frontal cortex biopsies in Alzheimer's disease: correlation with cognitive severity. Ann Neurol 27:457-464.

Diment S, Martin KJ, Stahl PD (1989) Cleavage of parathyroid hormone in macrophage endosomes illustrates a novel pathway for intracellular processing. J Biol Chem 264:13403-13406.

Doherty II JJ, Kay DG, Lai WH, Posner BI, Bergeron JJ (1990) Selective degradation of insulin within rat liver endosomes. J Cell Biol 110:35-42.

Dowson JH (1982) Neuronal lipofuscin accumulation in ageing and Alzheimer's dementia: a pathogenic mechanism? Br J Psychiatry 140:142-148.

Dreyer RN (1994) Processing of the pre-beta-amyloid protein by cathepsin D is enhanced by a familial Alzheimer's's disease mutation. Eur J Biochem 224:265-271.

Dunn WA Jr (1990) Studies on the mechanisms of autophagy: maturation of the autophagic vacuole. J Cell Biol 110:1935-1945.

Einstein G, Bautista P, Patel V, Kenna M, Melone L, Fader R, Karson K, Saunders A, Hulette C, Roses A, Schmechel D (1995) Does apoEimmunoreactivity mark vulnerable neurons in Alzheimer's disease? Alzheimer's Res 1:22.

Erickson AH and Blobel G (1983) Carboxyl-terminal proteolytic processing during biosynthesis of the lysosomal enzymes beta-glucuronidase and cathepsin D. Biochemistry 22:5201-5205.

Estus S, Golde TE, Younkin SG (1992) Normal processing of the Alzheimer's disease amyloid $\beta$ protein precursor generates potentially amyloidogenic carboxyl-terminal derivatives. $\Lambda \mathrm{nn} N Y$ Acad Sci 674:138-148.

Friede RL (1965) Enzyme histochemistry of neuroglia. Prog Brain Res 15:35-47.

Goate A, Chartier-Harlin M-C, Mullan M, Brown J, Crawford F, Fidani L, Guiffra L, Haynes A, Irving N, James L, Mant R, Newton P, Rooke K, Roques P, Talbot C, Percicak-Vance M, Roses A, Williamson R, Rosson M, Owen M, Hardy J (1991) Segregation of a missense mutation in the amyloid precursor protein gene with familial Alzheimer's disease. Nature 349:704-706.

Golde TE, Estus S, Younkin LH, Selkoe DJ (1992) Processing of the amyloid protein precursor to potentially amyloidogenic derivatives. Science 255:728-730.

Gorenstein C, Bundman MD, Leu PJ, Olds JL, Ribak CE (1985) Dendritic transport. I. Colchicine stimulates the transport of lysosomal enzymes from cell bodies to dendrites. J Neurosci 5:2009-2017.

Gordon PB, Hoyvik H, Seglen PO (1992) Prelysosomal and lysosomal connections between autophagy and endocytosis. Biochem J 283:361-369.

Gordon PB, Seglen PO (1988) Prelysosomal convergence of autophagic and endocytic pathways. Biochem Biophys Res Commun 151:409-478.

Griffiths G, Hoflack B, Simons K, Mellman I, Kornfeld S (1988) The mannose 6-phosphate receptor and the biogenesis of lysosomes. Cell $52: 329-341$.

Haas V, Sparks L (1995) Cortical cathepsin D activity and immunolocalizatin in Alzheimer's disease, critical coronary artery disease, and aging. Mol Chem Neuropathol, in press.

Haass C, Hung AY, Schlossmacher MG, Teplow DB, Selkoe DJ (1993) $\beta$-amyloid peptide and a $3 \mathrm{kDa}$ fragment are derived by distinct cellular mechanisms. J Biol Chem 268:3021-3024.

Haass C, Koo EH, Mellon A, Huyng AY, Selkoe DJ (1992) Targeting of cell-surface beta-amyloid precursor protein to lysosomes: alternative processing into amyloid-bearing fragments. Nature 357:500-503.

Han SH, Einstein G, Weisgraber KH, Strittmatter WJ, Saunders A, Pericak VM, Roses AD, Schmechel DE (1994a) Apolipoprotein E is localized to the cytoplasm of human cortical neurons: a light and electron microscopic study. J Neuropathol Exp Neurol 53:535-544.

Han SH, Hulette C, Saunders AM, Einstein G, Pericak VM, Strittmatter WJ, Roses AD, Schmechel DE (1994b) Apolipoprotein E is present in hippocampal neurons without neurofibrillary tangles in Alzheimer's disease and in age-matched controls. Exp Neurol 128:13-26.

Ho K-C, Gwozdz JT, Hause LL, Antuono PG (1992) Correlation of neuronal cell body size in motor cortex and hippocampus with body height, body weight, and axonal length. Int $J$ Neurusci 65:147-153.

Hoflack B, Kornfeld S (1985) Purification and characterization of a cation-dependent mannose 6-phosphate receptor from murine P388D1 macrophages and bovine liver. J Biol Chem 260:12008-12014.

Hsu S-M, Raine L, Fanger H (1981) Use of avidin-biotin-peroxidase complex (ABC) in immunoperoxidase techniques: a comparison between $\mathrm{ABC}$ and unlabeled antibody (PAP) procedures. J Histochem Cytochem 29:577-580.

Idriss JM, Jonas AJ (1991) Vitamin $\mathbf{B}_{12}$ transport by rat liver lysosomal membrane vesicles. J Biol Chem 266:9438-9441.

Klausner RD (1989) Sorting and traffic in the central vacuolar system. Cell 57:703-706.

Koo EH, Squazzo SL (1994) Evidence that production and release of amyloid beta-protein involves the endocytic pathway. J Biol Chem 269:17386-17389.

Kornfeld S (1992) Structure and function of the mannose 6-phosphate/ insulin-like growth factor II receptors. Annu Rev Biochem 61:307-330.

Kornfeld S, Mellman I (1989) The biogenesis of lysosomes. Annu Rev Cell Biol 5:483-525.

Ladror US, Snyder SW, Wang TW, Holzman T, Kraffı GA (1994) Cleavage at the amino and carboxyl termini of Alzheimer's amyloid- $\beta$ by cathepsin D. J Biol Chem 269:184232-18428.

LaVail JH, LaVail MM (1974) Retrograde axonal transport in the central nervous system. Science 176:1416-1417.

Lemansky P, Hasilik A, VonFigura K, Helmy S, Fishman J, Fine RE, Kedersha NL, Rome LH (1987) Lysosomal enzyme precursors in coated vesicles derived from the exocytic and endocytic pathways. J Cell Biol 104:1743-1748.

Levy-Lahad E, Wasco WS, Poorkaj P, Romano DM, Oshima J, Pettingell WH, Yu C, Jondro PD, Schmidt SD, Wang K, Crowley AC, Fu Y-H, Guenette SY, Galas D, Nemens E, Wijsmlan EM, Bird TD, Schellenberg GD, Tanzi RE (1995) Candidate gene for the chromosome 1 familial Alzheimer's disease locus. Science 269:973-977.

Mahley RW (1988) Apolipoprotein E: cholesterol transport protein with expanding role in cell biology. Science 240:622-630.

Mann DMA, Sinclair KGA (1978) The quantitative assessment of lipofuscin pigment, cytoplasmic RNA and nucleolar volume in senile dementia. Neuropathol Appl Neurobiol 4:129-135.

Mann D, Yates PO, Marcyniak B (1984) Changes in nerve cclls of the nucleus basalis of Meynert in Alzheimer's disease and their relationship to aging and to the accumulation of lipofuscin pigment. Mech Ageing Dev 25:189-204.

Masliah E, Mallory M, Alford M, Ge N, Mucke L (1995) Abnormal synaptic regeneration in hAPP695 transgenic and APOE knockout mice. In: Research advances in Alzheimer's disease and related disorders (Iqbal K, Mortimer JA, Winblad B, Wisniewski HM, eds), pp 405-414. Chichester: Wiley.

Matus A, Green GDJ (1987) Age-related increase in a cathepsin D-like protease that degrades brain microtubule-associated proteins. Biochemistry 26:8083-8086.

Mirra SS, Heyman A, McKeel D, Sumi SM, Crain BJ, Brownlee LM, Vogel FS, Hughes JP, van Belle G, Berg L (1991) The consortium to establish a registry for Alzheimer's disease (CERAD). Part II. Standardization of the neuropathologic assessment of Alzheimer's disease. Neurology 41:479-486.

Mullan M, Crawford F (1993) Genetic and molecular advances in Alzheimer's disease. Trends Neurosci 16:398-403.

Nakamura Y, Takeda M, Suzzuki H, Hattori H, Tada K, Hariquelis S, Hashimoto S, Nishimura T (1991) Abnormal distribution of cathepsins in the brain of patient with Alzheimer's disease. Neurosci Lett 130:195-198.

Nathan BP, Bellosta S, Sanan DA, Weisgraber KH, Mahley RW, Pitas RE (1994) Differential effects of apolipoproteins E3 and E4 on neuronal growth in vitro. Science 264:850-852.

Neve RL, Kammesheidt A, Hohmann CF (1992) Brain transplants of cells expressing the carboxyl-terminal fragment of the Alzheimer's amyloid protein precursor cause specific neuropathology in vivo. Proc Natl Acad Sci USA 89:3448-3452.

Nixon RA, Cataldo AM (1991) Lysosomal proteolysis in Alzheimer's brain: possible roles in neuronal cell death and amyloid formation. In: 
Frontiers of Alzheimer's research (Ishii T, Allsop D, Selkoe D, eds), pp 133-146. Amsterdam: Elsevier.

Nixon RA, Cataldo AM (1993) The lysosomal system in neuronal cell death: a review. Ann NY Acad Sci 679:87-109.

Nixon RA, Cataldo AM (1994) Frec radicals, protcolysis, and the degeneration of neurons in Alzheimer's disease: how essential is the $\beta$-amyloid link? Neurobiol Aging 15:463-469.

Nixon RA, Cataldo A (1995) The endosomal-lysosomal system of neurons: new roles. Trends Neurosci 18:489-496.

Nixon RA, Cataldo A, Mann DMA, Paskevich PA, Hamilton DJ, Wheelock TR (1993) Abnormalities of lysosomal proteolysis in neurons in Alzheimer's disease and Down's syndrome: possible relationship to $\beta$-amyloid deposition. In: Alzheimer's disease: advances in clinical and basic research (Corain B, Iqbal K, Nicolini M, Winblad B, Wisniewski H, Zatta P, eds), pp 441-450. New York: Wiley.

Nixon RA, Cataldo AM, Paskevich PA, Hamilton DJ, Wheelock TR, Kanaley-Andrews L (1992) The lysosomal system in neurons: involvement at multiple stages of Alzheimer's disease pathogenesis. Ann NY Acad Sci 674:65-88.

Nixon RA, Marotta CA (1984) Degradation of neurofilament proteins by purified human brain cathepsin D. J Neurochem 43:507-516.

Pannese E, Luciano L, Inrato S, Reale E (1976) Lysosomes in normal and degenerating neuroblasts of the chick embryo spinal ganglia: a cytochemical and quantitative study by electron microscopy. Acta Neuropathol (Berl) 36:209-220.

Parton RG, Dotti CG (1993) Cell biology of neuronal endocytosis. J Neurosci Res 36:1-9.

Rebeck GW, Reiter JS, Strickland DK, Hyman BT (1993) Apolipoprotein $E$ in sporadic Alzheimer's disease: allelic variation and receptor interactions. Neuron 11:575-580.

Renfrew CA, Hubbard AL (1991) Degradation of epidermal growth receptor in rat liver. Membrane topography through the lysosomal pathway. J Biol Chem 266:21265-21273.

Riederer MA, Soldati T, Shapiro AD, Lin J, Pfeffer SR (1994) Lysosome biogenesis requires Rab9 function and receptor recycling from endosomes to the trans-Golgi network. J Cell Biol 125:572-582.

Roberts VJ, Gorenstein C (1987) Examination of the transient distribution of lysosomes in neurons of developing rat brains. Dev Neurosci 9:255-264.

Roses AD (1994) Apolipoprotein E affects the rate of Alzheimer's disease expression: beta-amyloid burden is a secondary consequence dependent on APOE genotype and duration of disease. J Neuropathol Exp Neurol 53:429-437.

Roses AD (1995) Pcrspcctive: on the metabolism of apolipoprotein E and the Alzheimer's diseases. Exp Neurol 132:149-156.

Sahagian GG (1984) The mannose 6-phosphate receptor: function, biosynthesis and translocation. Biol Cell 51:207-214.

Sahagian GG, Novikoff PM (1994) Lysosomes. In: The liver: biology and pathobiology, 3rd ed (Arias IM, Boyer JL, Fausto N, Jakoby WB, Schachter DA, Shafritz DA, eds), pp 275-291. New York: Raven.
Sawant PL, Desai ID, Tappel AL (1964) Factors affecting the lysosomal membrane and availability of enzymes. Arch Biochem Biophys 105:247-253.

Schwagerl AL, Mohan PS, Cataldo AM, Vonsattel JP, Kowall NW, Nixon RA (1995) Elcvated levels of the cndosomal-lysosomal protcinase cathepsin D in cerebrospinal fluid in Alzheimer's disease. J Neurochem 64:443-446.

Seglen PO, Bohley P (1992) Autophagy and other vacuolar protein degradation mechanisms. Experientia 48:158-172.

Sherrington R, Rogaev EI, Liang Y, Rogaeva EA, Levesque G, Ikeda M, Chi H, Lin C, Li G, Holman K, Tsuda T, Mar L, Foncin J-F, Bruni AC, Montesi MP, Sorbi S, Rainero I, Pinessi L, Nee L, Chumakov I, Pollen D, Brookes A, Sanseau P, Polinsky RJ, Wasco W, DaSilva HAR, Haines JL, Pericak-Vance MA, Tanzi RE, Roses AD, Fraser PE, Rommens JM, St. George-Hyslop PH (1995) Cloning of a gene bearing missense mutations in early-onset familial Alzheimer's disease. Nature 375:754-760.

Siakotos AN, Armstrong D (1975) Age pigment, a biochemical indicator of intracellular aging. In: Advances in behavioral biology, Vol 16 (Ordy JM, Brizzee KR, eds), pp 369-397. New York: Plenum.

Strittmatter WJ, Weisgraber KH, Huang DY, Dong LM, Salvesen GS, Pericak-Vance M, Schmeckel D, Saunders AM, Goldgaber D, Roses $\mathrm{AD}$ (1993) Binding of human apolipoprotein $\mathrm{E}$ to synthetic amyloid beta peptide: isoform-specific effects and implications for late-onset Alzheimer's disease. Proc Natl Acad Sci USA 90:8098-8102.

Strous GJ, van Kerkhof P, Dekker J, Schwartz AL (1988) Metalloendoprotease inhibitors block protein synthesis, intracellular transport, and endocytosis in hepatoma cells. J Biol Chem 263:18197-18204

Swaab DF (1991) Brain aging and Alzheimer's disease, "wear and tear" versus "use it or lose it." Neurobiol Aging 12:317-324.

Tagawa K, Maruyama K, Ishiomura S (1992) Amyloid $\beta / \Lambda 4$ precursor protein (APP) processing in lysosomes. In: Proteases and protease inhibitors in Alzheimer's disease pathogenesis, Vol 674 (Banner CD, Nixon RA, eds), pp 129-137. New York: New York Academy of Sciences.

Terry RD, Masliah E, Salmon DP, Butters N, DeTeresa R, Hill R, Hansen LA, Katzman R (1991) Physical basis of cognitive alterations in Alzheimer's disease: synapse loss in the major correlate of cognitive impairment. Ann Neurol 30:572-580.

Teuchert-Noodt G, Breuker KH, Dawir RR (1991) Neuronal lysosomes accumulation in degrading synapses of sensory-motor and limbic subsystems in the duck Anas platyrhynchos: indication of rearrangements during avian brain development? Dev Neurosci 13:151-163.

Trowbridge IS (1991) Endocytosis and signals for internalization. Curr Opin Cell Biol 3:634-641.

Villanova M, Kowai M, Lubke U, Oh SJ, Penny G, Six J, Ccutcrick C, Martin JJ, Cras P (1993) Rimmed vacuoles of inclusion body myositis and oculopharyngeal muscular dystrophy contain amyloid precursor protein and lysosomal markers. Brain Res 603:343-347.

Yankner BA, Dawes LR, Fisher S, Villa-Komaroff L, Oster-Granite ML, Neve R (1989) Neurotoxicity of a fragment of the amyloid precursor associated with Alzheimer's disease. Science 245:417-420. 